\title{
Along the New Keynesian Phillips Curve with Nominal and Real Rigidities
}

\author{
James M. Nason ${ }^{\dagger}$ \\ Department of Economics \\ Rm 997, Buchanan Tower \\ 1873 East Mall \\ Vancouver, BC V6T 1Z1 \\ email : nason@econ.ubc.ca
}

\author{
George A. Slotsve ${ }^{\dagger}$ \\ Department of Economics \\ Zulauf Hall 506 \\ Northern Illinois University \\ DeKalb, Il 60115-2854 \\ email : gslotsve@niu.edu
}

First Draft : July 29, 2002

Current Draft : July 8, 2003

\begin{abstract}
We construct a New Keynesian Phillips curve (NKPC) in which the inflation fundamental is nominal unit labor costs. This NKPC yields estimates of the fraction of price constrained firms consistent with previous studies. Although the NKPC predicts permanent shocks dominate price level movements at all horizons, our estimated NKPC explains over half of price level fluctuations with permanent shocks only at a three year horizon. We develop monetary business cycle models which contain different combinations of nominal and real rigidities to study this puzzle. Monte Carlo experiments indicate labor market search together with flexible prices replicate the empirical NKPC predictions. Models with sticky-prices are at odds with these observations. Thus, real rigidities in the labor market matter more for economically important monetary non-neutralities than do sticky prices.
\end{abstract}

Key Words : New Keynesian Phillips Curve; Sticky Prices; Labor Market Search; Common Cycle; Common Trend.

\section{JEL Classification Number: $E 3$ and E5}

† We thank David Andolfatto, Paul Gomme, Francisco Gonzalez, Alain Guay, Peter Perkins, B. Ravikumar, John Roberts, John Rogers, Argia Sbordone, Chris Sims, Henry Siu, Eric Smith, Gregor Smith, Carl Walsh, and participants at the 2002 Bank of Canada Phillips Curve Workshop for their comments and suggestions. The first author completed some of the work on this paper when he visited the Federal Reserve Bank of Atlanta. He wishes to thank the staff of that institution for its hospitality and support during his visit. The views in this paper represent those of the authors and are not necessarily those of either the Federal Reserve Bank of Atlanta, the Federal Reserve System, or any of its staff. Any errors in this paper are the responsibility of the authors. 


\section{Introduction}

A great comeback of the 1990s is the revival of Phillips curve research. Unlike earlier work that focused on identifying shocks that generate exogenous shifts in aggregate demand, much of the renewed Phillips curve research aims to identify inflationary expectations. This matters for business cycle theory and monetary policy. For example, a Phillips curve that depends more on forward-looking than backward-looking expectations allows policymakers to lower inflation with few costs. Such a favorable trade-off appears at odds with empirical evidence and views policymakers hold about the costs of a disinflation.

Forward-looking Phillips curve models depend on models of price setting by firms faced with nominal rigidities. These models have monopolistically competitive firms maximizing the expected discounted stream of their profits subject to a sticky price constraint that represents the nominal rigidity. The solution to the firms' problem can be cast as the new Keynesian Phillips curve (NKPC) in which inflationary expectations are forward-looking and real marginal cost drives inflation fundamentals.

This paper explores the connection between the NKPC and the traditional Phillips curve. We identify permanent and transitory shocks to the NKPC. The identification yields a NKPC decomposition common trend-common cycle that builds on work of Beveridge and Nelson (1981), Stock and Watson (1988), and Vahid and Engle (1993).

Our NKPC decomposition relies on nominal marginal costs acting as the inflation fundamental because real marginal costs reflects the common trend restriction. It is forwardlooking because real marginal cost equals inflation net of the expected present value of nominal unit labor cost growth. We show that the NKPC predicts that real marginal cost is white noise. Thus, the NKPC predicts that trend shocks dominate aggregate price level fluctuations in the short-run, over the business cycle, and in the long-run.

The NKPC common cycle restriction is based on a linear combination of inflationary expectations and expected future nominal marginal cost growth. This annihilates any serial correlation in expected inflation. Hence, the NKPC common cycle restrictions play the role of innovations to inflationary expectations, which reflect aggregate demand shocks. 
The attention lavished on the NKPC stems from its ability to approximate actual inflation dynamics. ${ }^{1}$ Sbordone (2002), Gali and Gertler (1999), and Gali, Gertler, and López-Salido (2001) report empirical success with the NKPC. The latter two papers include lagged inflation to improve the fit of the NKPC on U.S. and European data, but report backward-looking inflationary expectations are not economically important. ${ }^{2}$

We find support for the NKPC common trend-common cycle decomposition in a U.S. sample of GDP deflator and nominal unit labor cost that runs from 1960Q1 to 2001Q4. The common cycle restriction yields an estimate that half of U.S. final goods firms are price constrained, which is similar to Sbordone (2002), but smaller than those reported by Gali and Gertler (1999). ${ }^{3}$ The forecast error variance decomposition of the NKPC common trendcommon cycle decomposition rejects the prediction that trend shocks are the only source of price level movements at all horizons. These shocks contribute more than 50 percent of the variation in the price level only at three year and longer forecast horizons.

We construct a dynamic stochastic general equilibrium (DSGE) monetary model with Calvo (1983) staggered price setting. This version of the Yun (1996) sticky price model fails to replicate any aspect of the sample NKPC common trend-common cycle decomposition. Instead, the Yun-sticky price model generates an aggregate price level completely dependent on trend shocks, which matches the NKPC prediction.

Gali and Gertler (1999) suggest the business cycle propagation mechanism of the NKPC is weak because it lacks a real rigidity. This motivates us to introduce one - a non-

\footnotetext{
${ }^{1}$ Other classes of monetary models provide a good fit to different aspects of U.S. inflation. Ireland (1999) estimates a game-theoretic monetary policy model and finds it captures long-run inflation dynamics. Nason and Cogley (1994) show a canonical dynamic stochastic general equilibrium monetary model replicates shortrun inflation dynamics identified in a structural vector autoregression of output and inflation.

${ }^{2}$ Fuhrer (1997), Roberts (1995, 1997, and 2001), and Rudd and Whelan (2001), among others, test traditional Phillips curves, with adaptive expectations, against the forward-looking NKPC and reject it.

${ }^{3}$ Gali and Gertler (1999) use generalized method of moments (GMM) to estimate the NKPC. This approach imputes inflationary expectations to the choice of instruments, which Ma (2002) and Nason and Smith (2003) show has undesirable properties. Sbordone (2002) minimizes the distance between price level dynamics restricted by a NKPC and the actual price level. This is akin to the two-step two-stage least squares estimator West (1989) develops to estimate the present discounted value model of stock prices.
} 
Walrasian labor market - to the Yun (1996) sticky price model. The model integrates sticky prices with the Andolfatto (1996) and Merz (1995) real business cycle (RBC) model with labor market search. ${ }^{4}$ The search process is costly for firms and households. A matching technology brings these agents together to form ongoing employment relationships. Since the competitive spot labor market is replaced with a strategic bargaining process in which the efforts of firms and workers to find one another result in on-going but transitory relationships, aggregate demand variables become endowed with the persistence inherent in the labor market search equilibrium. This links aggregate demand shocks to inflation in a way Solow (1976) argues is essential to understand Phillips curve behavior. ${ }^{5}$

We simulate the labor market search DGSE model with and without sticky prices. The Monte Carlo experiments reveal the sticky price-labor market search model behaves about the same as the Yun (1996) sticky price model. Hence, this model is rejected by our sample NKPC common trend-common cycle decomposition. A flexible price-labor market search model generates estimates of the measure of price constrained firms, a FEVD of the price level with respect to permanent shocks, and a NKPC common trends-common cycle decomposition that is a good fit to the sample data. Thus, the sources and causes of economically important non-neutralities over the business cycle reside with real rigidities rather than the nominal rigidity of sticky prices

The next section develops the NKPC common trend-common cycle decomposition and reports empirical results. Section 3 presents our sticky-price DSGE model. Model calibration and the outcome of several Monte Carlo experiments are discussed in section 4. This section also discusses experiments in which labor market search is introduced as a real rigidity into sticky price and flexible price DSGE models. We conclude in section 5.

\footnotetext{
${ }^{4}$ Millard, Scott, and Sensier (1999), Den-Haan, Ramey, and Watson (2000), and Hussey (2001) also place labor market search in RBC models.

${ }^{5} \mathrm{~A}$ tradition exists of DSGE monetary models that reproduce the Phillips curve observation that real economic activity and inflation are negatively correlated. The list includes Greenwood and Huffman (1986), Chéron and Langot (1999), Cooley and Quadrini (1999), and Walsh (2002). These papers study an unconditional implication of the Phillips curve. Our approach is conditional on the predictions of the NKPC.
} 


\section{The New Keynesian Phillips Curve}

The NKPC is derived from the optimal pricing conditions of a monopolistically competitive final good firm. Roberts (1995, 1997, and 2001), Fuhrer (1997), Gali and Gertler (1999), Rudd and Whelan (2001), Gali, Gertler, and López-Salido (2001), and Sbordone (2002) have examined the empirical implications of the NKPC and its variants. We identify the permanent and transitory shocks of the NKPC.

\subsection{A NKPC Specification}

Roberts (1995) shows that several sticky-price models yield the NKPC. Typical is the Calvo (1983) staggered price setting mechanism. Sticky prices arise because only a fraction, $1-\mu$, of monopolistically competitive final goods firms are able to set and commit to a new price, $P_{C, t}$, between dates $t-1$ and $t$. Aggregate price index, $P_{t}$, dynamics are restricted by

$$
P_{t}=\left[(1-\mu) P_{C, t}^{1-\xi}+\mu\left(\frac{m^{*}}{\gamma^{*}} P_{t-1}\right)^{1-\xi}\right]^{1 /(1-\xi)}, \quad 1<\xi
$$

where $\xi, m^{*}$, and $\gamma^{*}$ is the demand elasticity, steady state money growth, and non-stochastic growth of labor augmenting technology change, respectively. Assume the aggregator of final

demand (in physical units) firms face is $Y_{D, t}=\left[\int_{0}^{1} y_{D, j, t}^{(\xi-1) / \xi} d j\right]^{\xi /(\xi-1)}$, where $y_{D, j, t}$ represents demand (in physical units) firm $j$ faces. This implies the demand schedule of the $j$ th firm is

$$
y_{D, j, t}=\left(\frac{P_{j, t}}{P_{t}}\right)^{-\xi} Y_{D, t}
$$

where firm $j$ charges $P_{j, t}$ for its output and all firms take $Y_{D, t}$ and $P_{t}$ as given. Subsequent to cost minimization, profit maximization leads to the optimal commitment price

$$
P_{C, t}=\left(\frac{\xi}{\xi-1}\right)\left[\frac{\mathbf{E}_{t}\left\{\sum_{i=0}^{\infty}\left(\beta \mu\left[\frac{m^{*}}{\gamma^{*}}\right]^{-\xi}\right)^{i} \Gamma_{t+i} \phi_{t+i} Y_{D, t+i} P_{t+i}^{\xi}\right\}}{\mathbf{E}_{t}\left\{\sum_{i=0}^{\infty}\left(\beta \mu\left[\frac{m^{*}}{\gamma^{*}}\right]^{1-\xi}\right)^{i} \Gamma_{t+i} Y_{D, t+i} P_{t+i}^{\xi-1}\right\}}\right], \quad 0<\beta<1
$$

where $\mathbf{E}_{t}\{\cdot\}, \beta^{i} \Gamma_{t+i}$, and $\phi_{t}$ represent the mathematical expectations operator conditional on date $t$ information, the date $t+i$ (stochastic) discount rate all firms face, real marginal 
cost, and aggregate demand for final goods, respectively.

Sticky price dynamics force monopolistically competitive firms to be forward-looking when price setting. This gives the NKPC its forward-looking character, which is developed by linearizing the price aggregator (1) and the optimal price rule (3) (subsequent to detrending) to construct the equilibrium law of motion of the log price level

$$
\ln \left[P_{t}\right]=\mu \ln \left[P_{t-1}\right]+(1-\mu)\left(1-\frac{\mu}{\mathcal{B}}\right) \sum_{j=0}^{\infty}\left(\frac{\mu}{\mathcal{B}}\right)^{j} \mathbf{E}_{t} \ln \left[\Phi_{t+j}\right], \quad \mathcal{B} \equiv \frac{m^{*}}{\beta \gamma^{*}}
$$

where constants are ignored. ${ }^{6}$ The NKPC ties price level persistence to the fraction of firms unable to commit to a new price between dates $t-1$ and $t$. The equilibrium law of motion (4) also shows that price level fluctuations are driven by the forward-looking "annuity value" of the expected future path of nominal marginal cost. Thus, the NKPC predicts that permanent movements in nominal marginal cost dominate price level fluctuations. This yields a null of NKPC, transitory shocks are unimportant for price level movements at impact, over the business cycle, and in the long-run. A rejections of this null occurs when the price level deviates in an economically and statistically important way from its annuity value path. ${ }^{7}$

Usually, real marginal cost is cast as the NKPC's fundamental. However, the presentvalue relation (4) yields a NKPC Phillips curve in which nominal marginal cost is the fundamental. It also implies that inflation dynamics are restricted by the Euler equation

$$
(5) \Delta \ln \left[P_{t}\right]=(1-\mu) \Delta \ln \left[\Phi_{t}\right]-(1-\mu)\left(\frac{\mu}{\mathcal{B}}\right) \ln \left[\phi_{t}\right]+(1-\mu) \ln \left[\phi_{t-1}\right]+\left(\frac{\mu}{\mathcal{B}}\right) \mathbf{E}_{t} \Delta \ln \left[P_{t+1}\right]
$$

where $\Delta=1-\mathbf{L}$. Instead of a adaptive expectation-lagged inflation nominal rigidity characteristic of traditional Phillips curves, the lagged real marginal cost term of (5) has a real rigidity to generate persistent inflation. Thus, the Euler equation (5) predicts that a nominal (real) variable drives the forward-looking (backward-looking) component of the NKPC.

\footnotetext{
${ }^{6}$ Rotemberg (1982) develops a quadratic cost of adjustment model of monopolistic firm pricing behavior that yields similar price dynamics. Gregory, Pagan, and Smith (1993) study the econometric properties of models that give rise to stochastic difference equations identical to (4). Their results suggest caution about interpreting instrumental variable estimates of quadratic cost of adjustment models.

${ }^{7}$ Nason and Rogers (2003) examine this prediction for the present-value model of the current account.
} 
The price dynamics of (4) contains two insights about the NKPC. First, the price level and nominal marginal cost share a common trend or cointegrating relationship, $\phi_{t}=\Phi_{t} / P_{t}$. Subtract $\ln \left[\Phi_{t}\right]$ from both sides of equation (4), apply the usual present-value model algebra, and multiply the result through by minus one to produce

$$
\ln \left[\phi_{t}\right]=\left(\frac{\mu}{1-\mu}\right) \Delta \ln \left[P_{t}\right]-\sum_{i=1}^{\infty}\left(\frac{\mu}{\mathcal{B}}\right)^{i} \mathbf{E}_{t} \Delta \ln \left[\Phi_{t+i}\right] .
$$

Equation (6) sets real marginal cost equal to (a multiple of) inflation minus the expected present-value of nominal marginal cost growth. This view of the NKPC reveals real marginal cost to be forward-looking. Real marginal cost represents the transitory component of inflation unanticipated by the expected future path of nominal marginal cost growth. The null of the NKPC restricts real unit labor costs to be white noise.

Another prediction of the NKPC is that the price level and nominal marginal cost share a common cycle in the sense of Vahid and Engle (1993). A common cycle exists in the NKPC if a linear combination of inflation and nominal marginal cost growth is unpredictable conditional on their histories and the history of real marginal cost. The NKPC contains a common cycle because the present-value relation (4) implies

$$
\Delta \ln \left[P_{t}\right]-\mu_{\mathcal{B}} \Delta \ln \left[\Phi_{t}\right]=\frac{1}{\mu}\left[\mathbf{E}_{t} \Delta \ln \left[P_{t+1}\right]-\mathcal{E}_{\Phi, t}\right], \quad \mu_{\mathcal{B}} \equiv \frac{(1-\mu)(\mathcal{B}-\mu)}{\mu^{2}}
$$

where $\mathcal{E}_{\Phi, t}=\mu \mu_{\mathcal{B}}\left\{\mathbf{E}_{t-1} \Delta \ln \left[\Phi_{t}\right]+\left(\mathbf{E}_{t}-\mathbf{E}_{t-1}\right) \ln \left[\Phi_{t}\right]+\sum_{j=1}^{\infty}(\mu / \mathcal{B})^{j}\left(\mathbf{E}_{t} \Delta \ln \left[\Phi_{t+j}\right]-(\mu / \mathcal{B})\left(\mathbf{E}_{t}-\right.\right.\right.$ $\left.\left.\left.\mathbf{E}_{t-1}\right) \ln \left[\Phi_{t+j-1}\right]\right)\right\}$. The linear combination of inflation and nominal marginal cost growth of (7) removes all the serial correlation from inflationary expectations with the expected future path in nominal marginal cost growth and innovations in nominal marginal cost, $\mathcal{E}_{\Phi, t}$.

\subsection{NKPC Common Trend Prediction: Estimates and Tests}

We proxy nominal marginal cost with the ratio of hourly compensation to output per hour, $W_{t} h_{t} / Y_{t}$, where $W_{t}$ is the nominal wage, $h_{t}$ is hours, and $Y_{t}$ is aggregate output. ${ }^{8}$ This

\footnotetext{
${ }^{8}$ Sbordone (2002) and Gali and Gertler (1999) show that marginal cost is equivalent to $U L C$ based on the labor demand elasticity of a Cobb-Douglas technology of a monopolistic competitive firm.
} 
is a measure of nominal unit labor costs, $U L C_{t} \cdot{ }^{9}$ The price level is the GDP deflator. The sample period is $1960 Q 1-2001 Q 4, T=168$, with lags available beginning with $1955 Q 1$.

We use the maximum likelihood estimator (MLE) of Johansen $(1988,1991)$ to test for a common trend in the price level and ULC. The tests are conditional on a third-order vector EC mechanism (VECM). This $\operatorname{VECM}(3)$ corresponds to case $1 *$ of Osterwald-Lenum (1992). ${ }^{10}$ MacKinnon, Haug, and Michelis (1999) report five percent critical values of [15.88, 9.17] for the likelihood ratio (LR)-maximum test and [20.25, 9.17] for the LR-trace test given a bivariate case $1 *$ model. The estimated LR-maximum and LR-trace statistics are [12.98, $8.23]$ and $[21.20,8.23]$, respectively. Thus, the latter test is unable to reject a common trend in the price level and ULC, but the former test does.

We report two other cointegration tests because these results are inconclusive and Johansen's tests suffer from small sample problems. The Engle and Granger (1987) cointegration test first regresses $\ln \left[P_{t}\right]$ on a constant and $\ln \left[U L C_{t}\right]$, saves the residuals, and regresses these residuals on an own lag and three lags of first differences to produce a $t$-ratio of -3.34 of the largest autoregressive root. A $t$-ratio this negative fails to reject a common trend at the five percent level according to MacKinnon (1991). Boswijk (1994) constructs a Wald test for a simultaneous equations model which uses a two-stage least squares (2SLS) estimator. The Wald statistic of 11.82 falls between the ten and five percent critical values Boswijk tabulates (his table B.3). These tests lend support to the hypothesis that the price level and nominal unit labor cost cointegrate.

The ML estimate is $\phi_{M L E, t}=-\varpi_{C T-M L E}\left(\ln \left[P_{t}\right] \ln \left[U L C_{t}\right] 1\right)^{\prime}$, where $\varpi_{C T-M L E}=$ $\left[\begin{array}{lll}1 & -1.0810 & 6.8170\end{array}\right]$. Johansen (1991) provides a test (distributed $\chi^{2}$ with one degree of freedom) of the theoretical cointegrating vector, $\varpi_{C T}$. This test cannot reject the theoretical

\footnotetext{
${ }^{9}$ The index of hourly compensation (output per hour of all persons) in the non-farm business sector is labeled compnfb (ophnfb) in the Federal Reserve Bank of St. Louis' FRED databank. The ratio of compnfb to ophnfb is adjusted by the assumed steady state markup and labor's share prior to estimation.

${ }^{10} \mathrm{~A}$ likelihood ratio test for the lag length of the log levels VAR of the price level and $U L C$ - beginning with 12 lags - cannot reject a four lag specification. The AIC gives the same result. Also, the likelihood ratio test statistic of the case 1 VECM against the case $1 *$ VECM is 4.12 with a p-value of 0.04 , which rejects the restricted trends model at the five percent level.
} 
cointegrating relation of (6) at standard significance levels.

\subsection{NKPC Common Cycle Prediction: Estimates and Tests}

Vahid and Engle (1993) discuss the motivation, algebra, and measurement of common cycles. The NKPC common cycle can be interpreted as the common feature of inflation and $U L C$ growth, $\varpi_{C C}=\left[\begin{array}{ll}1 & -\mu_{\mathcal{B}}\end{array}\right]$, because it is an unobserved factor that drives both, in the sense that their linear combination is unpredictable. Thus, a common feature test of the NKPC involves a "search" for the linear combination of inflation and $U L C$ growth that is uncorrelated with the relevant past, the information set of the $\operatorname{VECM}(3)$.

There are several common feature tests. Two employ the canonical correlations, $\lambda$, of inflation and $U L C$ growth, conditional on the $\operatorname{VECM}(3)$ information set. Inflation and $U L C$ growth share a common feature if the smallest $\lambda=0$. Vahid and Engle (1993) develop a

common feature test, $-(T-4) \sum_{i=1}^{f} \ln \left(1-\lambda_{i}^{2}\right)$, that is asymptotically distributed $\chi^{2}\left(f^{2}+5 f\right)$, where $f=1,2$ and $i=1$ denotes the smallest $\lambda$. There also is a $F$-test due to Rao (1973) that has superior small sample properties, according to Engle and Issler (1995). We calculate squared canonical correlations of 0.0513 and 0.8243 . The associated p-values are 0.19 (0.21) and $0.00(0.00)$ for the $\chi^{2}(F-)$ test. These tests indicate the null is not rejected for the smallest canonical correlation, while the largest is statistically different than zero. Thus, inflation and $U L C$ growth share a common feature, the NKPC common cycle of (7).

It remains to estimate $\mu$, the fraction of price constrained monopolistically competitive firms. Vahid and Engle show that a 2SLS regression provides a common feature test, and also recovers the common feature vector. Conditional on the $\operatorname{VECM}(3)$ information set acting as instruments, the estimated 2SLS regression is

$$
\Delta \ln \left[P_{t}\right]=\begin{gathered}
0.2384 \\
(0.0876)
\end{gathered}+\underset{(0.0800)}{0.8203} \Delta \ln \left[U L C_{t}\right]
$$

The test statistic of instrument validity is 9.32 , which has a p-value of 0.16 given six degrees of freedom. ${ }^{11}$ This gives more support to the inflation and $U L C$ growth common cycle. Since

\footnotetext{
${ }^{11}$ When the instrument matrix drops the first lag of inflation and ULC growth and uses the second lag of
} 
the slope coefficient of the 2SLS regression is $\mu_{\mathcal{B}}$, we have to calibrate $\mathcal{B}$ to calculate $\mu$. We set $\beta=1.03^{-0.25}, m^{*}=\exp \{0.0167\}$, and $\gamma=0.0047$, where $m^{*}$ and $\gamma$ are based on U.S. data; see section 4.1 for details. This calibration yields $\mu_{2 S L S}=0.5292$ with a standard error of 0.0081 . This implies prices change twice a year on average.

Vahid and Engle describe a common cycle MLE of $\mu$ that stacks the common feature regression on top of the $\operatorname{ECM}(3)$ regression of nominal $U L C$ growth. The ML estimate of $\mu$ is 0.5192 with a standard error of 0.0153. A test of the common cycle restriction compares the $\operatorname{VECM}(3)$ under the common cycle restriction against an unrestricted $\operatorname{VECM}(3)$. This LR test has ten degrees of freedom and a p-value of 0.55. Along with the tests of the squared canonical correlations and 2SLS instrument validity, the LR test provides evidence in favor of the NKPC common cycle of (7). Also, the 2SLS and ML estimates of $\mu$ are close, statistical significant, and similar to estimates reported by Sbordone (2002), among others. The next section presents stylized facts about the NKPC which depend on $\varpi_{C T}$ and $\varpi_{C C}$.

\subsection{The Vahid-Engle-BNSW Decomposition of the NKPC}

Vahid and Engle show that a bivariate time series with a common trend and a common cycle possess a Beveridge and Nelson (1981) and Stock and Watson (1988) decomposition. The Beveridge, Nelson, Stock, Watson-Vahid and Engle (BNSW-VE) decomposition involves only the cointegrating vector, the common feature vector, and the levels data. The NKPC predicts the cointegration vector is $\varpi_{C T}=\left[\begin{array}{ll}1 & -1\end{array}\right]$ and the common feature vector is $\varpi_{C C}=\left[\begin{array}{ll}1 & -\mu_{\mathcal{B}}\end{array}\right] .{ }^{12}$ Stack these vectors into the matrix

$$
\left[\begin{array}{ll}
\pi_{\cdot, 1} & \pi_{\cdot, 2}
\end{array}\right]=\left[\begin{array}{c}
\varpi_{C T} \\
\varpi_{C C}
\end{array}\right]^{-1}
$$

The cyclical component of the NKPC is recovered from $\pi_{\cdot, 2} \times \varpi_{C T}\left(\ln \left[P_{t}\right] \ln \left[U L C_{t}\right]\right)$. The trend follows in the obvious way. ${ }^{13}$

real ULC rather then the first, the results are nearly identical.

${ }^{12}$ The NKPC common trend-common cycle decomposition accounts for disparities in $\varpi_{C T}$ and $\varpi_{C T-M L E}$.

${ }^{13}$ Vahid and Engle show that $\varpi_{C T}$ and $\varpi_{C C}$ are linearly independent. 
We present the common trend and common cycle of the NKPC BNSW-VE decomposition in the top and bottom windows of figure 1, respectively. The trend of the NKPC supports widely held views of the post-war history of the U.S. Phillips curve. The tight labor markets of the mid-1960s coincide with an increase in the (stochastic) NKPC trend. The trend falls with the recession that begins in late 1969. The 1970s sees a rising trend at the time of the first oil price shock, but not by the second. The tight monetary policy initiated in 1979 pushes the NKPC level trend below the actual price level in 1980 and it remains there until the economic expansion of the mid-1990s. The NKPC trend dips below the implicit GDP deflator just before the NBER peak dated 2001Q1.

The bottom window of figure 1 contains the the common cycle and NBER dated business cycle peaks (dash vertical lines) and troughs (the dot-dash vertical lines). The NKPC common cycle often fall between NBER dated peaks and troughs. Since the common cycle is a negative (up to a scalar) of real $U L C$, the plot of the common cycle and NBER business cycle dates argues that past a business cycle peak rising real ULC signals recovery from a recession. Thus, our view of the NKPC provides a measure of the trend and cycle of real economic activity which succinctly captures prior views of a well-behaved Phillips curve.

The NKPC common cycle-common trend decomposition provides information about the contribution of the identified shocks to GDP price and nominal $U L C$ fluctuations. ${ }^{14}$ Engle and Issler (1995) and Issler and Vahid (2001) develop methods to compute these forecast error variance decomposition (FEVD). The NKPC predicts common cycle innovations are irrelevant for price or inflation fluctuations, at all forecast horizons. Only innovations to the trend generate movements in inflation according to this Phillips curve. ${ }^{15}$

The FEVDs with respect to the trend shock appear in table $1 .{ }^{16}$ Trend shocks are

\footnotetext{
${ }^{14}$ This decomposition is unable to identify the trend (cyclical) shock as a supply (demand) shock.

${ }^{15}$ The volatility of the NKPC trend relative to the price level depends on the covariance of the trend and cycle innovations. When the covariance is negative, the price level is less volatile than the common trend.

${ }^{16}$ Engle and Issler (1995) and Issler and Vahid (2001) describe methods to calculate the forecast error variance decomposition. These authors set the trend innovation equal to the first difference of the common trend at the one-quarter ahead forecast horizon. At forecast horizon $j, j$ consecutive first differences of the common trend are summed to obtain the $j$-step-ahead trend innovation. Innovations to the cyclical
} 
responsible for more than a quarter of the variation in the GDP deflator at a four quarter horizon. By the end of two years, about 60 percent of the variation in the U.S. price level is driven by trend shocks. This reaches nearly 80 percent after three years and more than 98 percent by five years. This is evidence against the NKPC because shocks to the common cycle are economically important for the price level up to a three year forecast horizons.

$U L C$ possesses a similar FEVD with respect to the trend shock, with one caveat. This shock takes longer to become the dominate source of these fluctuations. However, the NKPC places no restrictions on these FEVDs.

This section has presented alternatives ways to model, estimate, test and study the NKPC. In our reading of the NKPC, the forward-looking character continues to be a hallmark of this approach to inflation dynamics. We also show that the inflation fundamental is $U L C$, rather than real $U L C$. Real ULC plays the role of the backward-looking component of the NKPC, which argues for real rigidities as a source of inflation dynamics. Given the VEBNSW decomposition provides mixed evidence about the trend and cycle implications of the NKPC, it suggests further study of the real rigidities hypothesis. The next section constructs a DSGE monetary model to study the contributions of real and nominal rigidities to inflation dynamics.

\section{DSGE Models with Nominal and Real Rigidities}

This section presents the DSGE models we study. We begin with the sticky-price DSGE model of Yun (1996). This model combines a cash-in-advance (CIA) constraint, cash and credit goods, and a Calvo-staggered price mechanism into a one-sector growth model. ${ }^{17}$ component are the residuals of the cyclical component regressed on the information set of our $\operatorname{VECM}(3)$ lagged $j$ times. Issler and Vahid orthogonalize the trend and cyclical innovations by 'regressing' the cyclical innovation on the trend innovation. This asserts the trend innovation is prior to the cyclical innovation. Footnote 11 and Appendix C of Issler and Vahid contain details.

${ }^{17} \mathrm{~A}$ variety of sticky-price technologies are used to study inflation dynamics in optimizing models. Examples include King and Wolman (1996), Nelson (1998), Ireland (2001), Kozicki and Tinsely (2001), and Sbordone (2001). A problem these models often face is their real side fails to generate fluctuations that resemble observed business cycle fluctuations. Ellison and Scott (2000) provide results and a discussion. 
A real rigidity is integrated into Yun's DSGE model with the labor market-search technology that Merz (1995), Andolfatto (1996), and Den-Haan, Ramey, and Watson (2000) use in a RBC setting. We also study a flexible price version of this DSGE model.

\subsection{The Final Goods Sector}

Final goods firms take addresses on the unit interval and produce differentiated goods to sell into a monopolistically competitive market. The $j$ th firm faces the demand schedule (2) in this market and has access to the constant returns to scale (CRS) technology, $F(k, h Z) \equiv k^{\theta}(h Z)^{1-\theta}, 0<\theta<1$, where (net) capital, $k$, and technology augmented labor hours, $Z h$, are combined to produce the final good. ${ }^{18}$

Monopolistic competition in the final goods market implies that final goods prices are a function of nominal marginal cost, $\Phi_{t}$. Marginal cost of the $j$ th final good firm is found from minimizing total cost, $\mathcal{T C}_{j, t}=R_{K, t} k_{j, t}+W_{t} h_{j, t}$, subject to the CRS technology, where $R_{K, t}$ is the nominal rental rate of capital. This implies the first-order necessary conditions (FONCs) $R_{k, t}=\Phi_{t} \theta y_{j, t} / k_{j, t}$ and $W_{t}=\Phi_{t}(1-\theta) y_{j, t} / h_{j, t}$. Subsequent to placing these optimality conditions into the cost function and exploiting the CRS technology, the total cost function of the $j$ th final good firm becomes $\mathcal{T C}_{j, t}=\Phi_{t} y_{j, t}-R_{k, t} \bar{K}_{t}$, where $\bar{K}_{t}$ denotes the exogenous fixed capital of date $t$. This yields the net profit function (in units of the output) of the $j$ th final good firm

$$
\frac{D_{j, t}}{P_{t}}=\left(\frac{P_{j, t}}{P_{t}}-\phi_{t}\right)\left(\frac{P_{j, t}}{P_{t}}\right)^{-\xi} Y_{D, t}-\frac{R_{K, t}}{P_{t}} \bar{K}_{t},
$$

given the demand schedule (2).

We study economies in which final goods prices are sticky and flexible. When final goods prices are flexible, real marginal cost is constant, $\phi=(\xi-1) / \xi$, in which prices are a constant markup over marginal costs. A final good firm whose behavior is restricted by the

\footnotetext{
${ }^{18}$ The labor market-search technology we outline below precludes fixed labor in production - as Yun (1996) does - because labor is not priced in a spot market. Instead, we posit an exogenous, economy-wide fixed amount of capital (e.g., infra-structure) all monopolistically competitive firms must have to produce; see the appendix for details.
} 
Calvo staggered price mechanism (1) faces the intertemporal profit maximization problem

$$
\mathbf{E}_{t}\left\{\sum_{i=0}^{\infty}(\beta \mu)^{i} \Gamma_{t+i}\left[\left(\left[\frac{m^{*}}{\gamma^{*}}\right]^{i} \frac{P_{C, t}}{P_{t+i}}-\phi_{t+i}\right)\left(\left[\frac{m^{*}}{\gamma^{*}}\right]^{i} \frac{P_{C, t}}{P_{t+i}}\right)^{-\xi} Y_{D, t+i}-\frac{R_{K, t}}{P_{t}} \overline{K_{t}}\right]\right\} .
$$

The FONC of $P_{C, t}$ leads to the forward-looking price-setting optimality condition (3). ${ }^{19}$

We close the final goods sector by constructing the aggregate dividend and production functions. Yun (1996) shows that aggregate demand is connected to aggregate supply through the aggregate supply price aggregator, $P_{A, t}{ }^{20}$ The definition of aggregate output $Y_{A, t} \equiv \int_{0}^{1} y_{A, j, t} d j$ and the aggregate demand schedule (2) yields $Y_{D, t}=\left(P_{t} / P_{A, t}\right)^{-\xi} Y_{A, t}{ }^{21}$ These facts lead to the aggregate real dividend function

$$
\frac{D_{t}}{P_{t}}=\left(\frac{P_{A, t}}{P_{t}}\right)^{\xi}\left[1-\theta \phi_{t}\right] Y_{A, t}-\frac{R_{K, t}}{P_{t}} K_{t}-\frac{W_{t}}{P_{t}} h_{t}
$$

Since the production technology is CRS, market clearing relative prices $R_{K, t} / P_{t}$ and $W_{t} / P_{t}$, and the definitions of aggregate capital and the employment rate result in $Y_{A, t}=K_{t}^{\theta}\left(h_{t} Z_{t}\right)^{1-\theta}$, which is the aggregate production function (and capital is net of its fixed component).

\subsection{The Household}

Households decisions cover capital accumulation, financial portfolios (to hold cash and government bonds), and labor supply. Felicity is summarized by

$$
u\left(c_{M, t}, c_{L, t}, \ell_{t}\right) \equiv \psi_{1} \ln \left[c_{M, t}\right]+\left(1-\psi_{1}\right) \ln \left[c_{L, t}\right]+\psi_{3} \frac{\ell_{t}^{1-\psi_{2}}}{1-\psi_{2}}
$$

where $0<\psi_{1}<1, \psi_{2} \neq 1,0 \leq \psi_{3}, c_{M, t}, c_{L, t}$, and $\ell_{t}\left(=1-h_{t}\right)$ are cash consumption, credit consumption, and household leisure, respectively. The household faces the budget constraint

\footnotetext{
${ }^{19}$ This imposes a symmetric equilibrium, $P_{j, t}=P_{t}$, either in sticky or flexible price equilibrium.

${ }^{20}$ This price aggregator is $P_{A, t}^{-\xi} \equiv\left[\int_{0}^{1} P_{j, t}^{-\xi} d j\right]$ and the associated dynamics are $P_{A, t}^{-\xi}=(1-\mu) P_{C, t}^{-\xi}+$ $\mu\left(m^{*} \exp \{-\gamma\} P_{A, t-1}\right)^{-\xi}$.

${ }^{21}$ This eliminates $P_{C, t}$ from the state of the economy leaving only current and lagged aggregate prices.
} 


$$
\begin{array}{r}
D_{t}+R_{K, t} k_{t}+W_{t} h_{t}+\left(1+R_{B, t}\right) B_{G, t}+M_{t}-A_{t+1} \\
=P_{t}\left[c_{M, t}+c_{L, t}+k_{t+1}-\left(1-\delta_{K}\right) k_{t}+T_{t}\right],
\end{array}
$$

the CIA constraint

$$
M_{t} \geq P_{t} c_{M, t},
$$

and the wealth constraint

$$
A_{t} \geq B_{G, t}+M_{t}-X_{t-1}
$$

where $0<\delta_{K}<1$, and $D_{t}, B_{G, t}, M_{t}, A_{t+1}, T_{t}$, and $X_{t-1}$ denote the dividends the household receives from final good firms, the government bonds this household owns at the beginning of date $t$, the cash the household carries over to date $t$ from the end of date $t-1$, the nominal wealth it takes from the end of date $t$ into the beginning of date $t+1$, a lump-sum tax which is levied on all households, and the total cash injection, respectively. Cash earns a zero nominal return. The government pays $R_{B, t}$ on its one-period unit discount bond.

\subsection{The Government}

The government engages in monetary and fiscal operations. Besides its expenditure, $G_{t}$, and tax collecting, $T_{t}$, activities, the government injects $X_{t}$ units of cash into the household sector, and conducts open market operations (OMOs) by issuing one-period unit discount bonds, $B_{G, t+1}$. Hence, the intertemporal budget constraint of the government is

$$
P_{t} T_{t}+\left(B_{G, t+1}-B_{G, t}\right)+\left(M_{t+1}-M_{t}\right)=P_{t} G_{t}+R_{B, t} B_{G, t}+X_{t} .
$$

We assume government spending evolves as an exogenous stochastic process around the steady state government spending-output ratio, $G_{t}=g_{t} Y_{D, t}$ and that $T_{t}=G_{t}$ at each 
date $t$. Along the equilibrium path, we impose zero net supply on government bonds. Cash injections obey $X_{t}=M_{t+1}-M_{t}$ and the monetary base evolves as $M_{t+1}=m_{t} M_{t}$, where $m_{t}$ is its growth rate. We maintain that $m_{t}$ is an exogenous stochastic process to avoid entangling the dynamics of our DSGE models with an arbitrary monetary policy rule.

\subsection{Household Optimality}

The household maximizes its expected lifetime utility subject to (10) - (12). Lifetime utility is the infinite discounted sum of felicity, where discounting is at rate $\beta$. This problem yields the consumption-based money demand function

$$
\frac{M_{t}}{P_{t}}=C_{t}\left[\frac{\psi_{1}}{1+\left(1-\psi_{1}\right) R_{B, t}}\right],
$$

where $C_{t} \equiv c_{M, t}+c_{L, t}$. Another implication is the household's stochastic discount factor

$$
\frac{\Gamma_{t}}{P_{t}}=\beta \mathbf{E}_{t}\left\{\frac{\psi_{1}}{P_{t+1} c_{M, t+1}}\right\} .
$$

Firms and the government discount at $\Gamma_{t}$ using (15). This discount factor, the CIA constraint (11), and the FONC with respect to $c_{L, t}$ produces the household "consumption function"

$$
C_{t}=\frac{M_{t}}{P_{t}}+\frac{\left(1-\psi_{1}\right)}{\Gamma_{t} P_{t}}
$$

In a flexible price economy, the purchasing power of cash balances adjusts to equate real balances plus the present value of the opportunity cost of the purchasing power of a dollar to aggregate consumption. A sticky-price economy forces the adjustment onto $C_{t}$ and $\Gamma_{t}$.

Optimal choices of employment hours and search hours by the typical household involve the usual trade-off between leisure and the rewards of labor market activity. The optimality condition of $h_{t}$ is

$$
\frac{\psi_{3}}{\left(1-h_{t}\right)^{\psi_{2}}}=\Gamma_{t} \frac{W_{t}}{P_{t}} .
$$

The household supplies labor up to the point where the dis-felicity of work equals the discounted real wage according to the optimality condition (17). This wage is determined in a 
perfectly competitive spot market.

The dynamic program the household solves produces three intertemporal optimality conditions. The Euler equation

$$
\frac{\Gamma_{t}}{P_{t}}=\beta \mathbf{E}_{t}\left\{\frac{\Gamma_{t+1}}{P_{t+1}}\left(1+R_{B, t+1}\right)\right\},
$$

describes optimal intertemporal choice for the household in the money market. It shows the interaction of the CIA constraint and next period's liquidity preference trade-off between consumption and the government's unit discount bond. The intertemporal trade-off between consumption and capital accumulation has a similar interpretation. This Euler equation

$$
\Gamma_{t}=\beta \mathbf{E}_{t}\left\{\Gamma_{t+1}\left[\frac{R_{t+1}}{P_{t+1}}+\left(1-\delta_{K}\right)\right]\right\}
$$

is determined by the FONC of $K_{t+1}$, the envelope condition for $K_{t}$, and the discount factor (15). Euler equation (19) shows the household is willing to postpone a unit of date $t$ consumption for the return additional capital is anticipated to yield during date $t+1$, conditional on the CIA constraint (11).

\subsection{Aggregate Equilibrium and Optimality}

Equilibrium requires that the goods, capital, money, government bond, and labor markets clear. Of these markets, the rental market for capital, the money market, the government bond market, and the labor market are perfectly competitive. Hence, agents treat the stochastic process that generates returns and the nominal wage, $\left\{R_{K, t+j}, R_{B, t+j}, W_{t+j}\right\}_{j=0}^{\infty}$, as given. The same holds for the exogenous shocks $\left\{Z_{t+j}, \bar{K}_{t}, G_{t+j}, X_{t+j}\right\}_{j=0}^{\infty}$. Also, firms and the government take the discount factor $\left\{\Gamma_{t+j}\right\}_{j=0}^{\infty}$ as given.

The equilibrium price level $P_{t}$ evolves differently in the presence of the Calvo-staggered price mechanism (1) (discussed in section 2.2) than in a flexible price economy. In either case, equilibrium decisions in the money market requires the consumption function (16), the stochastic discount factor (15), and 


$$
c_{M, t}=\frac{M_{t}}{P_{t}}
$$

which is the CIA constraint (11) at equilibrium.

The labor market yields an equilibrium decision rule from

$$
\frac{\psi_{3}}{\left(1-h_{t}\right)^{\psi_{2}}}=\Gamma_{t}\left(\frac{P_{t}}{P_{A, t}}\right)^{-\xi} \phi_{t}(1-\theta) K_{t}^{\theta} h_{t}^{-\theta} Z_{t}^{1-\theta} .
$$

This rests on the optimal labor supply of (17) and a firm's FONC with respect to hours.

An equilibrium decision rule for capital arises from the Euler equation for capital

$$
\Gamma_{t}=\beta \mathbf{E}_{t}\left\{\Gamma_{t+1}\left[\theta \phi_{t+1} K_{t+1}^{\theta-1}\left(h_{E, t+1} Z_{t+1}\right)^{1-\theta}+\left(1-\delta_{K}\right)\right]\right\},
$$

which brings together the Euler equation (19) and the nominal rental rate of capital. Equilibrium in the goods market also relies on the aggregate resource constraint

$$
\left(\frac{P_{t}}{P_{A, t}}\right)^{-\xi} Y_{t}=C_{t}+K_{t+1}+\left(1-\delta_{K}\right) K_{t}+G_{t} .
$$

The aggregate resource constraint (23) adds together the budget and wealth constraints of the household, (10) and (12), the government's budget constraint (13), and the dividend flow of final goods firms (8).

Any candidate equilibrium paths must satisfy the optimality conditions, laws of motion, and the aggregate resource constraint. The transversality condition of capital requires $\lim _{j \rightarrow \infty} \beta^{j} \mathbf{E}_{t}\left\{\Gamma_{t+j} K_{t+1+j}\right\}=0$, the sufficient condition of any candidate equilibrium.

\section{Comparing Sample and Theoretical NKPCs}

This section reports Monte Carlo experiments of the Yun (1996) sticky-price DSGE model to replicate the stylized facts of the sample NKPC common trend-common cycle decomposition. The calibration and solution strategies on which these experiments are based also appear. Labor market search is introduced into the sticky-price model to compare and contrast the implications for the NKPC of this real rigidity with the nominal rigidity of 
sticky-prices. We complete this study of the NKPC with a flexible price version of our monetary DSGE with labor market search.

\subsection{The Calibration, the Steady State, and Numerical Solutions}

We generate the approximate numerical solution of the DSGE model of section 3 from the linearized stochastically detrended variants of its optimality conditions, laws of motion, and equilibrium conditions. Real side aggregates are detrended with $\widehat{U}_{Y, t}=U_{Y, t} / Z_{t}$, aggregate prices with $\widehat{U}_{P, t}=U_{P, t} Z_{t} / M_{t}$, nominal wages with $\widehat{W}_{t}=W_{t} / M_{t}$, the stochastic discount factor $\widehat{\Gamma}_{t}=\Gamma_{t} Z_{t}$, and the real rental rate of capital $\widehat{R}_{K, t}=R_{K, t} / P_{t}$, where $U_{Y, t}=\left[Y_{D, t}, Y_{A, t}, C_{t}, K_{t+1}, G_{t}\right]$ and $U_{P, t}=\left[P_{t}, P_{A, t}, P_{C, t}\right]$.

Stochastic detrending is necessary because the labor augmenting technology shock evolves as a random walk with drift

$$
\ln \left[Z_{t+1}\right]=\ln \left[Z_{t}\right]+\gamma+\varepsilon_{t+1}, \quad 0<\gamma, \quad \varepsilon_{t+1} \sim \mathbf{N}\left(0, \sigma_{\varepsilon}^{2}\right)
$$

and money growth is a $\operatorname{AR}(1)$

$$
m_{t+1}=m^{*\left(1-\rho_{m}\right)} m_{t}^{\rho_{m}} \exp \left\{\eta_{m, t+1}\right\}, \quad\left|\rho_{m}\right|<1, \quad \eta_{m, t+1} \sim \mathbf{N}\left(0, \sigma_{\eta, m}^{2}\right),
$$

where $\ln \left[m_{t}\right]=\ln \left[M_{t+1}\right]-\ln \left[M_{t}\right]$. We assume the transitory components of the fixed component of capital and government spending are non-stochastic.

The numerical solution of the economy begins with linearizing the detrended optimality and equilibrium conditions of the economy. The system of interest contains the aggregate resource constraint (23), the equilibrium hours schedule (21), the consumption function (16), the law of motion of the aggregate price level which underlies the NKPC (4), and the Euler equation $K_{t+1}$, (22). The solution we conjecture is

$$
\widetilde{K}_{t+1}=\mu_{K} \widetilde{K}_{t}+\mu_{\mathcal{E}} \mathcal{E}_{t},
$$

where $\widetilde{K}_{t}=\ln \left[\widehat{K}_{t} / X^{*}\right]$ and the exogenous state vector $\mathcal{E}_{t}=\left[\begin{array}{ll}\varepsilon_{t+1} & \eta_{m, t+1}\end{array}\right]^{\prime}$. We apply methods Zadrozny (1998) and Sims (2000) develop to compute an approximate numerical solution. ${ }^{22}$

\footnotetext{
${ }^{22}$ The linearized DSGE model with sticky-prices generates a singular leading coefficient matrix in its
} 
We employ sample data and choices made in other RBC studies to calibrate model parameters. The calibration of the preference parameters $\beta$ and $\psi_{1}$ are 0.9950 and 0.7454 . The latter implies an interest elasticity of money demand of 1.5 percent based on the sample mean of the three-month U.S. T-bill rate. The remaining preferences parameters are taken from Andolfatto (1996), $\psi_{2}=2.0$ and $\psi_{3}=2.08$.

Our choices of technology and aggregate demand are standard. We let $\theta=0.35$ and $\delta_{K}=0.0195$. We assume a steady state markup of 1.10 , which yields $\xi=11.0$.

Our calibration of the impulse structure relies mostly on sample data. The deterministic growth rate, $\gamma$, of the economy is 0.0047 , which is calculated from the sample mean of measured total factor productivity. We choose $\sigma_{\varepsilon}=0.0085$ because this value of the standard deviation of the technology shock forces theoretical output growth to match its sample counterpart.

The parameters of the $\mathrm{AR}(1)$ process of money growth is estimated from sample data. We use the Federal Reserve Bank of St. Louis' monetary base series to calibrate the parameters of the money growth process. The mean growth rate is 0.0166. OLS estimates of the $\operatorname{AR}(1)$ of money growth yield $\rho_{m}=0.4456$ and $\sigma_{\eta, m}=0.0068 .^{23}$

\subsection{Monte Carlo Design}

We generate $\mathcal{J}=5000$ replications of the monetary DSGE models. A replication consists of 168 observations of the price level and $U L C \cdot{ }^{24}$ Next, the cointegrating vector of these synthetic time series is estimated for the case $1^{*} \operatorname{VECM}(3)$, according to Johansen stochastic difference equation. In this case, we employ computer programs made available by Chris Sims and described in Sims (2000).

${ }^{23}$ As previously mentioned we maintain the transitory components of the fixed capital component and government spending are nonstochastic. It remains to calibrate $g^{*}$. Its sample mean equals 0.1878 . The calibration of $\bar{K}^{*}$ is problematic. It cannot be constructed without observations on fixed capital. The closest notion is structures, but U.S. capital stock data reveals the ratio of structures to total capital is about 0.23 for the 1960 - 2000 sample. We assume 2.5 percent of capital is fixed. Experiments with values between 0.5 and 15 percent had little impact on the Monte Carlo experiments.

${ }^{24}$ We compute 372 artificial time series observations, but toss out observations $1, \ldots, 204$ to remove dependence on initial conditions. 
(1988, 1991). Conditional on this estimated cointegrating relation and three lags of artificial inflation and $U L C$ growth, the 2SLS regression of the growth rate of prices on a constant and the growth rate of $U L C$ is calculated to produce the common features vector. The slope coefficient of this regression also yields a theoretical estimate of $\mu$. The estimates of the cointegrating and common features vector are employed to construct the BNSW-VE decomposition and its FEVD. ${ }^{25}$ We report theoretical FEVDs in table 2. Figure 2 contains nonparametric densities of empirical distributions of $\mu$ drawn from the DSGE models and the asymptotic 95 percent confidence interval of $\mu_{2 S L S}$. Theoretical BNSW-VE common trends and common cycles appear in figures 3,4 , and 5 .

\subsection{Yun-Sticky-Price Experiments}

Results for the Yun (1996) sticky price DSGE model show it is at odds with the actual NKPC BNSW-VE decomposition. This is revealed by the second column of table 2 and figures 2 and 3. Table 2 contains the theoretical FEVDs of the aggregate price level with respect to permanent shocks, the associated one-standard deviation confidence intervals of these FEVDs (in brackets), and the sample FEVD of the GDP deflator for comparison. The FEVD and its one-standard deviation confidence intervals of the Yun-sticky-price model are all greater than 98 percent. The theoretical one-standard deviation confidence intervals indicate little uncertainty around this prediction of the Yun-sticky price model. Thus, the NKPC of this sticky price model is dominated by permanent shocks at all forecast horizons. Although this matches the NKPC prediction, it is far from the sample NKPC observations. Further evidence of the failure of the NKPC of the Yun (1996) sticky price DSGE model to match the sample NKPC BNSW-VE decomposition is found in figures 2 and 3. Figure 2 contains the asymptotic 95 percent confidence interval (the vertical dotted lines) of $\mu_{2 S L S}=0.5293$, and the densities of the ensembles of theoretical 2SLS estimates of $\mu .{ }^{26}$ The

\footnotetext{
${ }^{25}$ The ensemble mean of the second element of the cointegrating vector is approximately negative one by construction. Differences with the sample estimate are handled in the theoretical BNSW-VE decomposition.

${ }^{26}$ The non-parametric densities are estimated using the normal kernel $\mathcal{N}(x)=\exp \left\{-0.5 x^{2}\right\} / \sqrt{2 \pi}$ where $x$ is the distance between two points in the density. The density, $d(x)=\mathcal{J}^{-1} \sum_{i=1}^{\mathcal{J}} \mathcal{N}\left(\left[\mathcal{X}-\mathcal{X}_{i}\right] / h\right)$, plugs in the kernel, where $h$ is the bandwidth or smoothing parameter of the density and $\mathcal{X}_{i}$ is the $i$ th Monte Carlo
} 
Yun-sticky price model generates a mean of 0.8173 for this empirical distribution of $\mu$. This implies firms change prices every 5.5 quarters on average. Since this is more than twice the length we observe in sample, the associated density (the dashed density) is well to the right of the asymptotic 95 percent confidence interval of $\mu_{2 S L S}$ in figure 2. Thus, the restrictions the Yun-sticky price DSGE model places on the artificial data produces estimates of the fraction of price constrained firms that are much too large.

The NKPC BNSW-VE decomposition of the Yun-sticky price DSGE model appears in figure 3 . The top window of figure 3 shows that the NKPC common trend of this model falls on top of the sample GDP deflator. The resulting common cycle never wanders far from zero which gives a theoretical one-standard deviation confidence band nearly indistinguishable from zero. Thus, we conclude the actual data rejects the NKPC BNSW-VE decomposition of the Yun-sticky price DSGE model.

\subsection{Sticky-Price-Labor Search Experiments}

The failure of the Yun (1996) sticky price DSGE model is evidence the nominal rigidity of sticky prices alone is incapable of yielding a good fit to the NKPC BNSW-VE decomposition. Advice from Gali and Gertler (1999) suggests we approach this problem by adding a real rigidity, labor market search, to the Yun-sticky price model. The result is a DSGE which integrates the Calvo-staggered price mechanism (1) with the labor search technologies found in the RBC models of Merz (1995), Andolfatto (1996), and Den-Haan, Ramey, and Watson (2000).

Job search generate costs. We assume that a final good firm operates multiple plants identifying each plant with a job. ${ }^{27}$ Since job search precludes perfect competition in the labor market, an active plant of a final good firm and the aggregate household negotiate a labor contract over hours of employment, $h_{t}$, and the real wage, $W_{t} / P_{t}$, of an on-going plant-job match. A final good firm incurs a cost $v$ to fill a vacant plant-job, which follows replication of the 2SLS estimate of $\mu$. Silverman (1986) provides advice to compute $d(x)$, see pages $43-48$.

${ }^{27}$ Andolfatto (1996) points out that the assumption of a CRS production technology in the presence of job search identifies each plant-job with an operating plant. Hence, the aggregate measure of plants of final good firms and the measure of employed households are equivalent. 
Andolfatto (1996). ${ }^{28}$ The aggregate measure of plant-job matches is denoted $N_{t}$. The aggregate household devotes a total of $\left(1-N_{t}\right) S_{t}$ hours to job search and a final good firm posts $v_{j, t}$ plant-job vacancies during date $t$. We use the Den Haan, Ramey, and Watson (2000) constant returns to scale (CRS) matching function

$$
\mathcal{M}\left(V_{t},\left(1-N_{t}\right) S_{t}\right)=\frac{V_{t}\left[\left(1-N_{t}\right) S_{t}\right]}{\left(V_{t}^{\vartheta}+\left[\left(1-N_{t}\right) S_{t}\right]^{\vartheta}\right)^{1 / \vartheta}}, \quad 0<\vartheta,
$$

where $V_{t} \equiv \int_{0}^{1} v_{j, t} d j$ is the total number of plant-job vacancies. This flow of new plant-job matches plus the extant matches that do not separate gives the law of motion of $N_{t+1}$

$$
N_{t+1}=\mathcal{M}\left(V_{t},\left(1-N_{t}\right) S_{t}\right)+\left(1-\delta_{N}\right) N_{t}, \quad 0<\delta_{N}<1,
$$

where $\delta_{N}$ denotes the exogenous non-stochastic job separation rate. ${ }^{29}$ The employed and notemployed comprise the household sector. A match between a not-employed individual and a vacant plant-job occurs randomly. However, these probabilities are influenced indirectly when the not-employed and final good firms vary their search effort. For a not-employed individual or a final good firm with an open plant-job, the exogenous probabilities that a vacant plant-job is filled is denoted $\omega_{V, t}\left(=\mathcal{M}\left(V_{t},\left(1-N_{t}\right) S_{t}\right) / V_{t}\right)$ and that someone notemployed successfully finds work is $\omega_{S, t}\left(=\mathcal{M}\left(V_{t},\left(1-N_{t}\right) S_{t}\right) /\left[S_{t}\left(1-N_{t}\right)\right]\right)$, respectively. ${ }^{30}$

Households are either employed or not employed, in which case they engage in job search. An employed household enjoys an ongoing relationship with a plant-job of a final good firm. The ongoing nature of this relationship occurs because the job match continues from date $t$ into date $t+1$ with probability $1-\delta_{N}$. When a not-employed household attempts to move into employed status, the probability a job match occurs is $\omega_{S, t}$. In this case, the law of motion of the measure of employed households becomes

\footnotetext{
${ }^{28}$ Total recruitment costs represent a drain on aggregate output. This forces us to assume that $v$ shares the technology trend, but has a non-stochastic transitory component.

${ }^{29}$ Den Haan, Ramey, and Watson (2000) introduce an endogenous separation mechanism into their RBCsearch model. A linear approximation of their model is equivalent to adding an exogenous shock to the separation rate $\delta_{N}$ of the law of motion (28).

${ }^{30}$ The CRS search technology specification (27) bounds $\omega_{V, t}$ and $\omega_{S, t}$ between zero and one.
} 


$$
N_{t+1}=\left(1-\delta_{N}\right) N_{t}+\omega_{S, t}\left(1-N_{t}\right) S_{t}
$$

where $\left(1-N_{t}\right) S_{t}$ equals the average search effort of not-employed households.

Job search has an impact on household felicity (9). Not-employed households suffer a felicity loss of

$$
\psi_{5} \frac{\left(1-S_{t}\right)^{1-\psi_{4}}}{1-\psi_{4}}, \quad \psi_{4} \neq 1, \quad 0 \leq \psi_{5}
$$

when they give up leisure to search a fraction $S_{t}$ of their one unit of date $t$ time endowment. The leisure component of aggregate felicity becomes

$$
N_{t} \psi_{3} \frac{\left(1-h_{t}\right)^{1-\psi_{2}}}{1-\psi_{2}}+\left(1-N_{t}\right) \psi_{5} \frac{\left(1-S_{t}\right)^{1-\psi_{4}}}{1-\psi_{4}}
$$

because complete income and wealth insurance creates an aggregate household that is a weighted average of employed and not-employed households, where the weights reflect timevariation in aggregate employment. ${ }^{31}$

One other change is needed to close our labor market search DSGE model with money. The wealth constraint of a not-employed household differs from that of a employed household. The not-employed face transactions costs during job search. We assume these transactions costs rise linearly with search effort at rate $\varphi(>0)$. Hence, the not-employed household requires cash to engage in job search. Since the not-employed household faces a CIA constraint, the cash injection from the government represents the only available cash to pay the transactions search cost. Complete nominal insurance requires not-employed

\footnotetext{
${ }^{31}$ The appendix shows there exist complete income and wealth insurance arrangements that support the aggregation of the employed and not-employed households. Aggregation rests on the capital stocks, dividends received, cash held, and bonds owned by these households to be equal date-by-date. This assumes that employed and not-employed households hold equal endowments of capital and financial wealth at date zero. Further, we assume away any wealth disparities that are caused by ownership claims on final goods firms. However, if employed and not-employed households are initially given equal equity in final goods firms, the dividend flows will be equalized. Also, these results depend on the additive separability of felicity.
} 
households to be held harmless for these costs. This requires a nominal transfer from the employed to the not-employed. In this case, the aggregate wealth constraint becomes

$$
A_{t} \geq B_{G, t}+M_{t}-\left[1-\varphi\left(1-N_{t-1}\right) S_{t-1}\right] X_{t-1} .
$$

The term $\left[1-\varphi\left(1-N_{t-1}\right) S_{t-1}\right]$ reflects the nominal transfer employed households make to the not-employed to help finance their job search. ${ }^{32}$ Since increased job search lowers the size of the case injection the aggregate household receives, actions of the not-employed are correlated with nominal activity.

We follow the same practices to calibrate the newly introduced parameters as discussed in section 4.1. The not-employed preference parameters $\psi_{4}$ and $\psi_{5}$ equal two and 1.37, respectively. This helps to guarantee aggregate hours and employment match their sample counterparts. Cooley and Quadrini (1999) fix $1 / \vartheta$ at 0.6 . We do the same. ${ }^{33}$ The exogenous fixed separation rate equals 0.0848 which helps to set steady state employment and its sample counterpart equal. This calibration of $\delta_{N}$ is within the range Merz (1995), Den-Haan, Ramey, and Watson (2000), and Andolfatto (1996) use. The vacancy cost parameter $v=0.1050$ is taken from Andolfatto (1996). The steady state is also constructed to impose the endogenous probabilities $\omega_{V, t}=0.70$ and $\omega_{S, t}=0.60$ on the simulation experiments. We assume transactions-search costs represent a 0.1 percent loss in velocity at the steady state (in terms of sample GDP and the monetary base). This yields $\varphi=0.3060$.

Surprisingly, the introduction of labor market search to the Yun (1996) sticky price DSGE model has almost no impact on the theoretical BNSW-VE decomposition of the NKPC. The FEDVs of this model are a bit smaller than the "pure" sticky price model as shown in the column labeled 'search-sticky price model' of table 2 . The widest one-standard deviation confidence band of the theoretical FEVD of this model is at one quarter forecast

\footnotetext{
${ }^{32}$ If not, the money demand functions of employed and not-employed households do not lead to the aggregate money demand (14). Our full insurance scheme is outlined in the appendix. Sims (1998) discusses several related issues.

${ }^{33}$ This calibration is imposed on the labor contract surplus splitting rule. Hosios (1990) shows this causes the equilibrium wage process to be consistent with the socially optimal wage for several static search models.
} 
horizon and states that between 93 and 99.5 percent of the variation in the aggregate price level is explained by permanent shocks. This is the NKPC prediction, but is far from the sample FEVD of the GDP deflator with respect to permanent shocks that appears in the second column of table 2.

Figure 2 shows that the sticky price-labor search DSGE model generates a nonparametric density of $\mu$ not contained in the asymptotic 95 percent confidence interval of $\mu_{2 S L S}$. The mean of the ensemble of these theoretical estimates of the sticky price parameter is 0.6762. Hence, the addition of labor market search to the Yun (1996) sticky price model is unable to generate transitory price fluctuations sufficient to explain our estimates of the fraction of price constrained firms.

The common trend-common cycle decomposition of the sticky price-labor search DSGE model is found in figure 4. The theoretical NKPC common trend (the top window) closely follows the actual GDP deflator. The trends of the Yun-sticky price model and the sticky price-labor search model are nearly identical. These trends closely follow the sample trend of the U.S. GDP price deflator. Thus, it is not unexpected that the common cycle of the sticky price-labor search model is far from the sample NKPC common cycle.

In summary, sticky price models with and without labor market search are rejected by the data, conditional on the BNSW-VE decomposition of the NKPC. The reason is these models match the NKPC prediction that price level fluctuations are dominated by permanent shocks. This suggests it is important to snap the link between the price level and permanent shocks inherent in the sticky price framework.

\subsection{Flexible-Price-Labor Search Experiments}

This section reports on a DSGE model which replaces the Calvo-staggered price mechanism (1) with a flexible price regime. We find that flexible prices breaks the dominance of permanent shocks on the price level. However, prices continue to exhibit "stickiness" because of the real rigidity of labor market search. The transitory persistence non-Walrasian labor market contracts generate inhabits the aggregate price level. ${ }^{34}$

\footnotetext{
${ }^{34}$ The appendix provides details about the Nash-equilibrium labor contract.
} 
The FEVDs of the flexible price-labor search model appear in the last column of table 2. These theoretical FEVDs are larger than the sample FEVDs at 1, 2, and 4 quarter forecast horizons, but smaller beyond two year forecast horizons. The flexible price-labor search model predicts that permanent shocks contribute about 80 percent of the movement in the aggregate price level at a ten year forecast horizon. This theoretical prediction of the model is much less than the corresponding sample FEVD of nearly 100 percent. Nonetheless, the one-standard deviation confidence bands of the theoretical FEVDs always cover the sample FEVD, except at the ten year horizon and then just barely misses the sample FEVD. Hence, the flexible price-labor search model produces variation in its FEVD of the price level with respect to permanent shocks that replicates the sample FEVD.

Figure 2 shows that asymptotic 95 percent confidence interval of $\mu_{2 S L S}$ falls within the nonparametric density of $\mu$ of the flexible price-labor search model. This density is the solid line of figure 2. Almost 18.5 percent of the elements of the ensemble of these theoretical estimates of $\mu$ is contained in the asymptotic 95 percent confidence interval, [0.5133, 0.5450]. The mean of this ensemble is 0.5075 compared to $\mu_{2 S L S}=0.5293$. This is another piece of evidence in favor of real rigidities being an important part of the underlying structure that explain the NKPC observations.

The theoretical NKPC BNSW-VE common trend and common cycle of the flexible price-labor search model appear in figure 5. A striking feature of the theoretical common trend (the top window) and the common cycle (the bottom window) is that flexible prices and labor market search creates only slightly more persistence and about two-thirds more volatility in its NKPC common cycle than is observed in sample. The AR1 coefficients of the sample and the mean of the ensemble of theoretical NKPC common cycles are 0.93 and 0.94 , respectively. The standard deviation of these common cycles are 7.86 and 12.84 .

Figure 5 shows that the differences between the empirical and theoretical common trends and cycles are greatest around peaks and troughs. Otherwise, the one-standard deviation confidence band cover the sample NKPC common cycle, particularly after the recession of the early 1980s. Hence, we conclude the flexible price-labor search DSGE model is more successful at replicating the empirical NKPC than are the sticky price models. 


\section{Conclusion}

We accomplish several tasks in this paper. First, we develop a common cycle-common trend decomposition of the new Keynesian Phillips curve (NKPC). Nominal unit labor costs plays the role of the inflation fundamental, rather than real unit labor costs, in our Beveridge, Nelson, Stock, Watson-Vahid and Engle decomposition of the NKPC. The common trend of this decomposition restricts real unit labor costs to be the cointegrating relation of the NKPC. An implication is that the NKPC predicts trend shocks to nominal unit labor costs dominate price level movements at all forecast horizons. The common cycle restriction of our NKPC decomposition removes serial correlation from inflationary expectations with a linear combination of inflation and nominal unit labor cost growth.

Second, the last 40 years of U.S. GDP deflator and nominal unit labor costs data supports the NKPC, with one exception. Cointegration and common feature tests are unable to reject the presence of one common trend and one common cycle in this data. We also employ the sample common cycle restriction to estimate that about half of final goods firms in the U.S. are price constrained. These estimates are close to estimates reported elsewhere. The disparity between the data and the predictions of the NKPC trend-cycle decomposition NKPC arises in its forecast error variance decomposition (FEVD). Permanent shocks only begin to account for more than half of aggregate price level movements at forecast horizons of three years or more in our U.S. sample. Thus, the FEVD rejects the NKPC prediction that permanent shocks dominate price level fluctuations at all forecast horizons.

We construct and study several monetary dynamic stochastic general equilibrium (DSGE) models to realize our final task. Monte Carlo experiments show that a simple one-sector DSGE model with Calvo (1983) staggered price setting reproduces the NKPC predictions exactly. The price level shows no response to transitory shocks. This model also under-estimates the frequency of price changes in the aggregate economy. Hence, a DSGE model with only the nominal rigidity of sticky prices is unable to match the sample NKPC common trend-common cycle decomposition.

Earlier theories of the Phillips curve invoke real rigidities in labor markets to explain observed inflation dynamics. We pursue this idea with the introduction of labor market 
search to the sticky price DSGE model. The outcome of Monte Carlo experiments of the sticky price model is no different with the real rigidity than without it. The theoretical common trend-common cycle decomposition of the two models and the FEVDs are nearly identical. Thus, the NKPC of the DSGE model with sticky prices and labor market search clashes with our sample NKPC.

The flexible price-labor search DSGE model fares much better. Its theoretical NKPC matches many of the sample observations we study. Monte Carlo experiments of this model yield theoretical estimates of the fraction of price constrained firms that contains the sample estimate. These experiments also produce FEVD of the price level to permanent shocks that cover the sample FEVDs, at all but the longest forecast horizons. The only weakness of the flexible price-labor search DSGE model is that its common trend-common cycle decomposition exhibits somewhat more volatility than observed in our U.S. sample.

Our results challenge the New-Keynesian notion that nominal rigidities explain monetary non-neutralities at the business cycle horizons. We argue the flexible price-labor search DSGE model generates a better fit to the actual data. The real rigidity of labor market search better reflects the character of labor market imperfections in the aggregate economy because real rigidities produce more reasonable monetary non-neutralities at the business cycle horizons. This suggests the sources and causes of price level persistence and inflation dynamics reside in real rigidities, instead of nominal ones. Thus, the search for DSGE model to be used for policy analysis needs to focus on real rigidities that arise from economic primitives. 


\section{References}

Andolfatto, D., 1996, "Business Cycles and Labor Market Search", American Economic Review, 86, 112 - 132 .

Beveridge, S. and C.R. Nelson, 1981, "A New Approach to Decomposition of Economic Time Series into Permanent and Transitory Components with Particular Attention to Measurement of the Business Cycle", Journal of Monetary Economics, 7, 151 - 174.

Boswijk, H.P., 1994, "Testing for an Unstable Root in Conditional and Structural Error Correction Models", Journal of Econometrics, 63, 37 - 60.

Calvo, G.A., 1983, "Staggered Prices in a Utility-Maximizing Framework", Journal of Monetary Economics, 12, $383-398$.

Chéron, A. and F. Langot, 1999, "The Phillips and Beveridge Curves Revisited", Economics Letters, 69, $371-376$.

Cooley, T.F. and V. Quadrini, 1999, "A Neoclassical Model of the Phillips Curve Relation", Journal of Monetary Economics, 44, 165 - 193.

Den-Haan, W.J., G. Ramey, and J. Watson, 2000, "Job Destruction and the Propagation of Shocks", American Economic Review 90, 482 - 498.

Dixit, A.K. and J.E. Stiglitz "Monopolistic Competition and Optimum Product Diversity", American Economic Review, 67, 297 - 308.

Ellison, M. and A. Scott, 2000, "Sticky Prices and Volatile Output", Journal of Monetary Economics, 46, $621-632$.

Engle, R.F. and C.W.J. Granger, 1987, "Cointegration and Error Correction: Representation, Estimation, and Testing", Econometrica, 55, 251 - 130.

Engle, R.F. and J.V. Issler, 1995, "Estimating Common Sectoral Cycles", Journal of Monetary Economics, 35, 83 - 113.

Fuhrer, J.C., 1997, "The (Un)Importance of Forward-Looking Behavior in Price Specifications", Journal of Money, Credit, and Banking, 29, 338 - 350.

Fuhrer, J.C. and G.R. Moore, 1995, "Inflation Persistence", Quarterly Journal of Economics, $110,127-159$.

Gali, J. and M. Gertler, 1999, "Inflation Dynamics: A Structural Econometric Analysis", Journal of Monetary Economics, 44, 195 - 222.

Gali, J., M. Gertler, and J.D. López-Salido, 2001, "European Inflation Dynamics", European Economic Review, 45, 1237 - 1270. 
Greenwood, J. and G.W. Huffman, 1986, "A Dynamic Equilibrium Model of Inflation and Unemployment", Journal of Monetary Economics, 19, 203 - 228.

Gregory, A.W., A.R. Pagan, and G.W. Gregory, 1993, "Estimating Linear Quadratic Models with Integrated Processes", in in P.C.B. Phillips, ed., Models, Methods, $\underline{\text { and }}$ Applications of Econometrics, Basil Blackwell, Oxford, U.K..

Hosios, A.J., 1990, "On the Efficiency of Matching and Related Models of Search and Unemployment", Review of Economic Studies, 57, 279 - 298.

Hussey, R.M., 2001, "Evaluating Business Cycle Models with Labor Market Search", mimeo, Department of Economics, Duke University.

Ireland, P.N., 1999, "Does the Time-Consistency Problem Explain the Behavior of Inflation in the United States?", Journal of Monetary Economics, 44, 279 - 291.

Ireland, P.N., 2001, "Sticky-Price Models of the Business Cycle: Specification and Stability", Journal of Monetary Economics, 47, 3-18.

Issler, J.V. and F. Vahid, 2002, "Common Cycles and the Importance of Transitory Shocks to Macroeconomic Aggregates", Journal of Monetary Economics, 47, 449 - 475.

Johansen, S., 1988, "Statistical Analysis of Cointegration Vectors", Journal of Economic Dynamics and Control, 12, $231-254$.

Johansen, S., 1991, "Estimation and Hypothesis Testing of Cointegration Vectors in Gaussian Vector Autoregressive Models", Econometrica, 59, 1551 - 1580.

King, R.G., C.I. Plosser, and S.T. Rebelo, 1988, "Production, Growth, and Business Cycles: I. The Basic Neoclassical Model", Journal of Monetary Economics, 21, 195 - 232.

King, R.G. and M.W. Watson, 1994, "The Post-war U.S. Phillips Curve: A Revisionist Econometric History", Carnegie-Rochester Series on Public Policy, 41, 157-219.

King, R.G. and M.W. Watson, 1997, "Testing Long-Run Neutrality", Economic Quarterly, Federal Reserve Bank of Richmond, 83(Summer), 69-101.

King, R.G. and A.L. Wolman, 1996, "Inflation Targeting in a St. Louis Model of the 21st Century", Review, Federal Reserve Bank of St. Louis, 78(May/June), 83 - 108.

Kozicki, S. and P.A. Tinsely., 2001, "Dynamic Specifications in Optimizing Trend-Deviation Macro Models", mimeo, Faculty of Economics and Politics, University of Cambridge.

Ma, A., 2001, "GMM Estimation of the New Phillips Curve", Economics Letters 76, 411-417.

MacKinnon, J.G., 1991, "Critical Values for Cointegration Tests", in Long-Run Economic

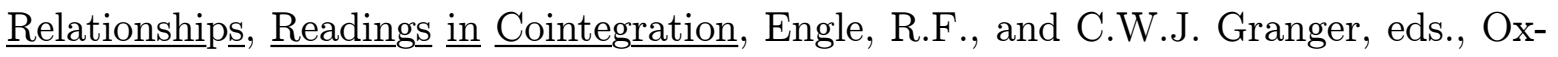
ford University Press, Oxford, U.K.. 
MacKinnon, J.G., A.A. Haug, and L. Michelis, 1999, "Numerical Distributions of Likelihood Ratio Tests of Cointegration", Journal of Applied Econometrics, 14, 563 - 577.

Merz, M., 1995, "Search in the Labor Market and the Real Business Cycle", Journal of Monetary Economics, 36, 269 - 300.

Millard, S., A. Scott, and M. Sensier, 1999, "Business Cycles and the Labour Market: Can Theory Fit the Facts?", Working Paper No. 93, Bank of England, London.

Nason, J.M. and T. Cogley, 1994, "Testing the Implications of Long-Run Neutrality for Monetary Business Cycle Models", Journal of Applied Econometrics, 9, S37-S70.

Nason, J.M. and J.H. Rogers, 2003, "The Present-Value Model of the Current Account Has Been Rejected: Round Up the Usual Suspects", Working Paper 2003-7, Federal Reserve Bank of Atlanta.

Nason, J.M. and G.W. Smith, 2003, "Identifying the New Keynesian Phillips Curve", manuscript, Department of Economics, Queen's University, Kingston, Ontario.

Nelson, E., 1998, "Sluggish Inflation and Optimizing Models of the Business Cycle", Journal of Monetary Economics, 42, 303 - 323.

Newey, W.K. and K.D.West, 1994, "Automatic Lag Selection in Covariance Matrix Estimation, Review of Economic Studies 61, 631 - 653.

Osterwald-Lenum, M., 1992, "Quantiles of the Asymptotic Distribution of the Maximum Likelihood Cointegration Rank Test Statistics, Oxford Bulletin of Economics and Statistics 54, $461-472$.

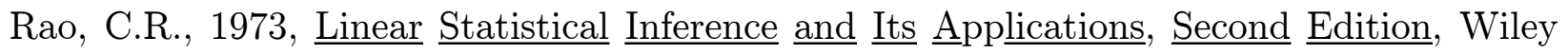
and Sons, Inc., New York, NY.

Roberts, J.M., 2001, "How Well Does the New Keynesian Sticky-Price Model Fit the Data", mimeo, Division of Research and Statistics, Board of Governors of the Federal Reserve System, Washington, DC.

Roberts, J.M., 1997, "Is Inflation Sticky", Journal of Monetary, Economics, 39, 173 - 196.

Roberts, J.M., 1995, "New Keynesian Economics and the Phillips Curve", Journal of Money, Credit, and Banking, 27, 975 - 984.

Rotemberg, J.J., 1982, "Monopolistic Price Adjustment and Aggregate Output", Review of Economic Studies, 49, 517 - 531.

Rudd, J. and K. Whelan, 2001, "New Tests of the New Keynesian Phillips Curve", FEDS Working Paper 2001 - 30, Board of Governors of the Federal Reserve System, Washington, DC. 
Sbordone, A.M., 2001, "An Optimizing Model of U.S. Wage and Price Dynamics", mimeo, Department of Economics, Rutgers University.

Sbordone, A.M., 2002, "Prices and Unit Costs: A New Test of Price Stickiness", Journal of Monetary Economics, 49, 235 - 456.

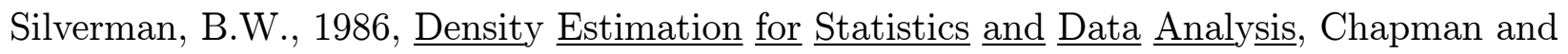
Hall, Ltd., London, England.

Sims, C.A., 1998, "Stickiness", Carnegie-Rochester Conference Series on Public Policy, 49, $317-356$.

Sims, C.A., 2000, "Solving Linear Rational Expectations Models", mimeo, Department of Economics, Princeton University.

Solow, R.M., 1976, "Down the Phillips Curve with Gun and Camera", in Inflation, Trade, and Taxes, Belsley, D.A., E.J. Kane, P.A. Samuelson, R.M. Solow, eds., Ohio State University Press, Columbus, Ohio.

Stock, J.H. and M.W. Watson, 1988, "Testing for Common Trends", Journal of the American Statistical Association, 83, 1097 - 1107.

Vahid, F. and R.F. Engle, 1993, "Common Trends and Common Cycles", Journal of Applied Econometrics, 8, $341-360$.

Walsh, C.E., 2002, "Labor Market Search and Monetary Shocks", mimeo, Department of Economics, University of California, Santa Cruz.

West, K.D., 1989, "Dividend Innovations and Stock Price Volatility", Econometrica 56, $37-61$.

Yun, T., 1996, "Nominal Rigidities, Money Supply Endogeneity, and Business Cycles", Journal of Monetary Economics, 37, 345 - 370.

Zadrozny, P.A., 1998, "An Eigenvalue Method of Undetermined Coefficients for Solving Linear Rational Expectations Models", Journal of Economic Dynamics and Control 22, $1353-1373$. 


\title{
Table 1. Forecast Error Variance Decomposition Sample Period: $\quad 1960 Q 1-2001 Q 4$
}

\author{
Percentage of Variance Explained by Trend Innovations \\ of BNSW-Engle-Vahid Decomposition
}

\begin{tabular}{ccc} 
Horizon & $\begin{array}{c}\text { Implicit } \\
\text { GDP Deflator }\end{array}$ & $\begin{array}{c}\text { Nominal } \\
\text { Unit Labor Cost }\end{array}$ \\
\hline 1 & 2.70 & 0.28 \\
2 & 8.80 & 2.01 \\
4 & 26.38 & 10.79 \\
8 & 60.12 & 41.34 \\
12 & 78.37 & 65.00 \\
16 & 86.55 & 77.52 \\
20 & 91.44 & 85.41 \\
40 & 98.05 & 96.65 \\
\hline
\end{tabular}

The trend innovation equals the first difference of the common trend at the one-quarter forecast horizon. At forecast horizon $j, j$ consecutive first differences of the common trend are summed to obtain the $j$-step-ahead trend innovation. Innovations to the cyclical component are the residuals of the cyclical component regressed on the information set of our $\operatorname{VECM}(3)$ lagged appropriately (the information set lagged $j$ times); see Engle and Issler (1995) and Issler and Vahid (2001) for details. 
Table 2. Forecast Error Variance Decomposition

One Standard Deviation Confidence Intervals

FEVDs of Price w/r/t Trend, Generated by DSGE Models

\begin{tabular}{|c|c|c|c|c|}
\hline Horizon & $\begin{array}{l}\text { Sample } \\
\text { PGDP }\end{array}$ & $\begin{array}{c}\text { Yun-Sticky } \\
\text { Price Model }\end{array}$ & $\begin{array}{l}\text { Search-Sticky } \\
\text { Price Model }\end{array}$ & $\begin{array}{c}\text { Search-Flexible } \\
\text { Price Model }\end{array}$ \\
\hline \multirow[t]{2}{*}{1} & \multirow[t]{2}{*}{2.70} & 99.03 & 96.06 & 10.03 \\
\hline & & {$\left[\begin{array}{ll}98.10 & 99.94\end{array}\right]$} & {$\left[\begin{array}{ll}92.98 & 99.53\end{array}\right]$} & {$\left[\begin{array}{ll}1.40 & 19.11\end{array}\right]$} \\
\hline \multirow[t]{2}{*}{2} & \multirow[t]{2}{*}{8.80} & 99.38 & 98.22 & 17.66 \\
\hline & & {$\left[\begin{array}{ll}98.80 & 99.96\end{array}\right]$} & {$\left[\begin{array}{ll}96.99 & 99.80\end{array}\right]$} & {$\left[\begin{array}{ll}3.23 & 34.85\end{array}\right]$} \\
\hline \multirow[t]{2}{*}{4} & \multirow[t]{2}{*}{26.38} & 99.71 & 99.19 & 29.36 \\
\hline & & {$\left[\begin{array}{ll}99.44 & 99.98\end{array}\right]$} & {$\left[\begin{array}{ll}98.66 & 99.92\end{array}\right]$} & {$\left[\begin{array}{ll}7.11 & 56.06\end{array}\right]$} \\
\hline \multirow[t]{2}{*}{8} & \multirow[t]{2}{*}{60.13} & 99.88 & 99.65 & 44.72 \\
\hline & & {$\left[\begin{array}{ll}99.76 & 99.99\end{array}\right]$} & {$\left[\begin{array}{ll}99.46 & 99.97\end{array}\right]$} & {$\left[\begin{array}{ll}15.69 & 76.15\end{array}\right]$} \\
\hline \multirow[t]{2}{*}{12} & \multirow[t]{2}{*}{78.37} & 99.93 & 99.79 & 54.52 \\
\hline & & {$\left[\begin{array}{ll}99.87 & 100.00\end{array}\right]$} & {$\left[\begin{array}{ll}99.70 & 99.98\end{array}\right]$} & {$\left[\begin{array}{ll}23.50 & 85.28\end{array}\right]$} \\
\hline \multirow[t]{2}{*}{16} & \multirow[t]{2}{*}{86.55} & 99.95 & 99.86 & 61.32 \\
\hline & & {$\left[\begin{array}{ll}99.91 & 100.00\end{array}\right]$} & {$\left[\begin{array}{ll}99.81 & 99.99\end{array}\right]$} & {$\left[\begin{array}{ll}30.86 & 90.09\end{array}\right]$} \\
\hline \multirow[t]{2}{*}{20} & \multirow[t]{2}{*}{91.44} & 99.97 & 99.90 & 66.30 \\
\hline & & {$\left[\begin{array}{ll}99.94 & 100.00\end{array}\right]$} & {$\left[\begin{array}{ll}99.86 & 99.99\end{array}\right]$} & {$\left[\begin{array}{ll}37.92 & 92.87\end{array}\right]$} \\
\hline \multirow[t]{2}{*}{40} & \multirow[t]{2}{*}{98.05} & 99.99 & 99.96 & 79.25 \\
\hline & & {$\left[\begin{array}{ll}99.98 & 100.00\end{array}\right]$} & {$\left[\begin{array}{ll}99.96 & 100.00\end{array}\right]$} & {$\left[\begin{array}{ll}58.96 & 97.81\end{array}\right]$} \\
\hline
\end{tabular}

The values in brackets are the 16th and 84th percentiles of the FEVDs generated from 5000 replications of the DSGE models. 
Figure 1: The U.S.Phillips Curve

The Phillips Curve Trend (solid line) and GDP Price Level (dotted line)

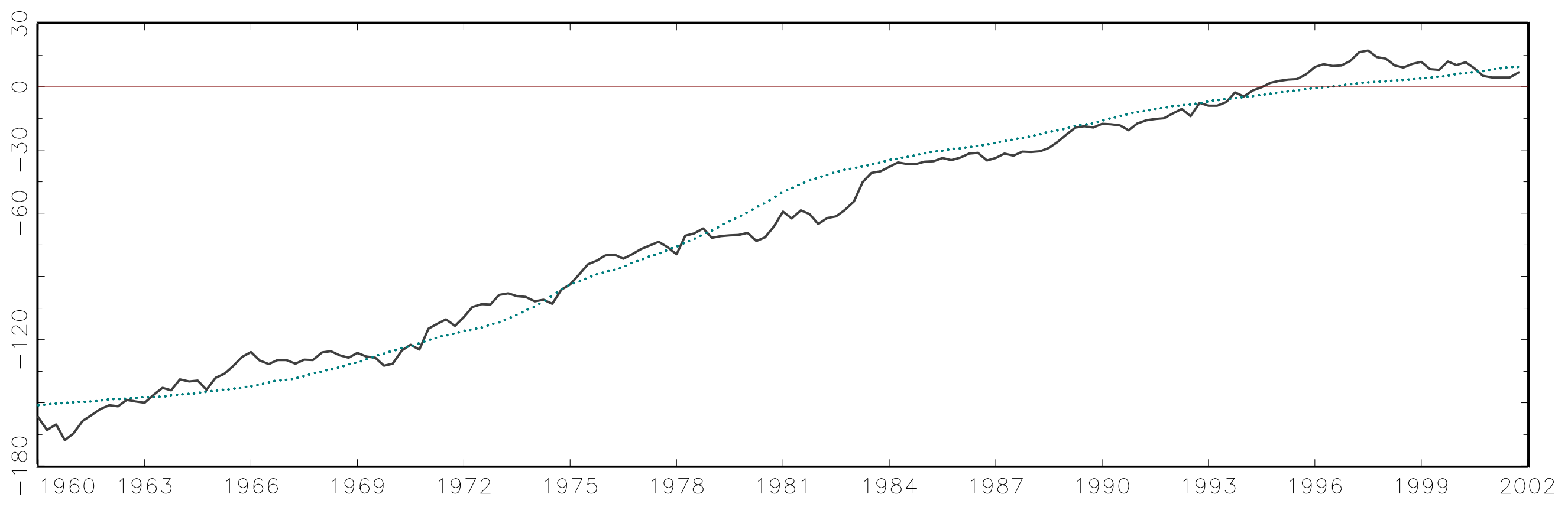

The Phillips Curve Cycle and NBER Business Cycle (Peak dash line, Trough dot-dash line)

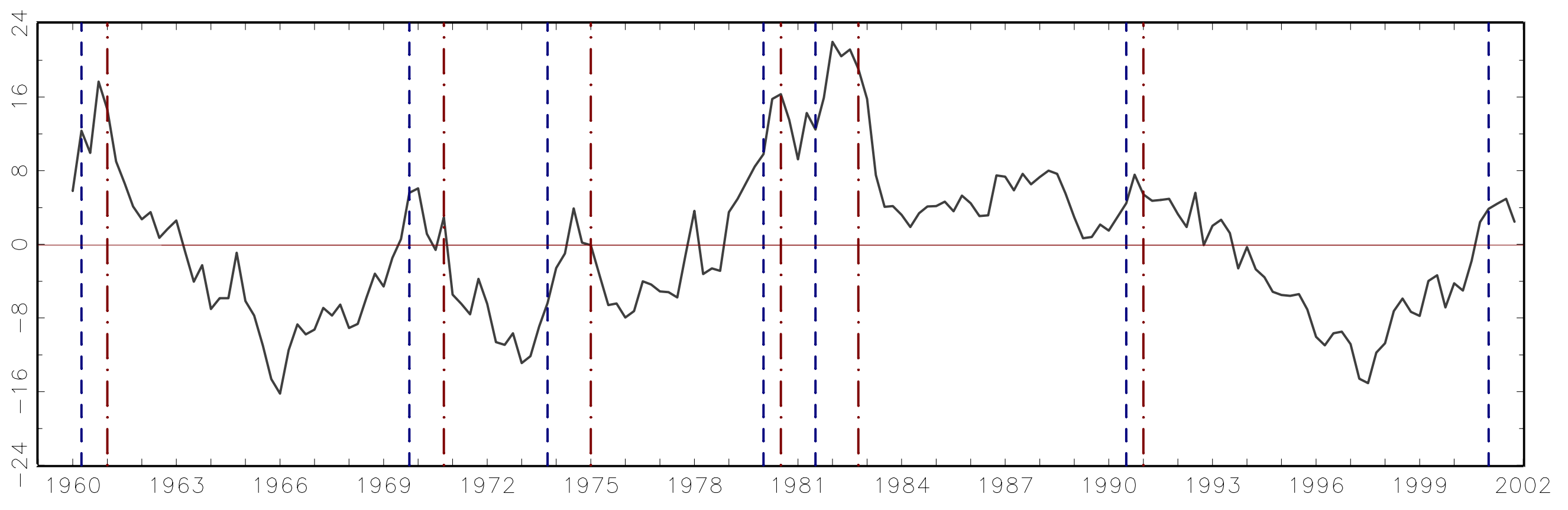




\section{Figure 2: Theoretical Densities of $\mu$}

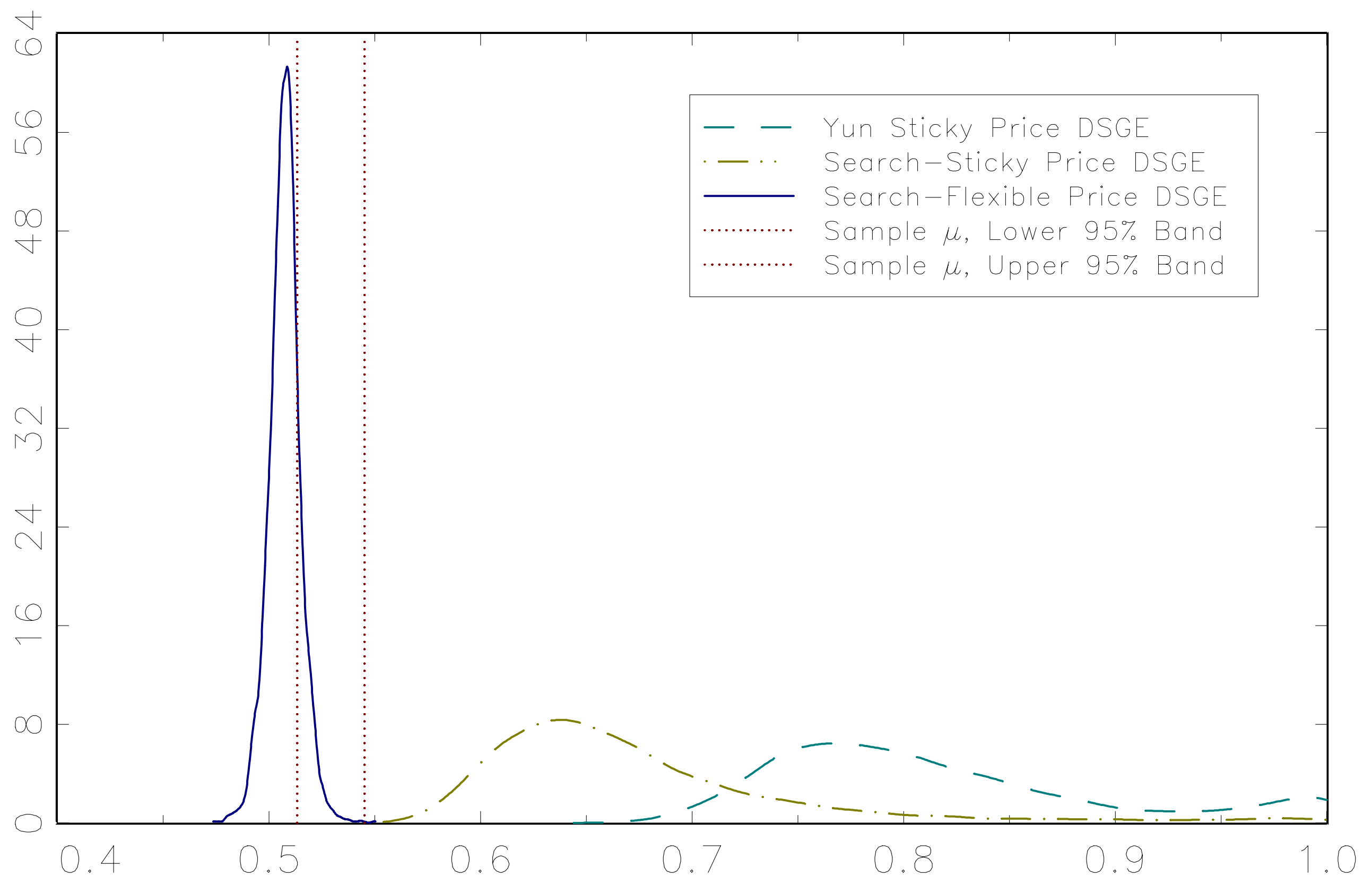


Figure 3: Yun-Sticky Price DSGE Model

Yun-Sticky Price Phillips Curve Trend, Sample Phillips Curve Trend, and Actual Price Level

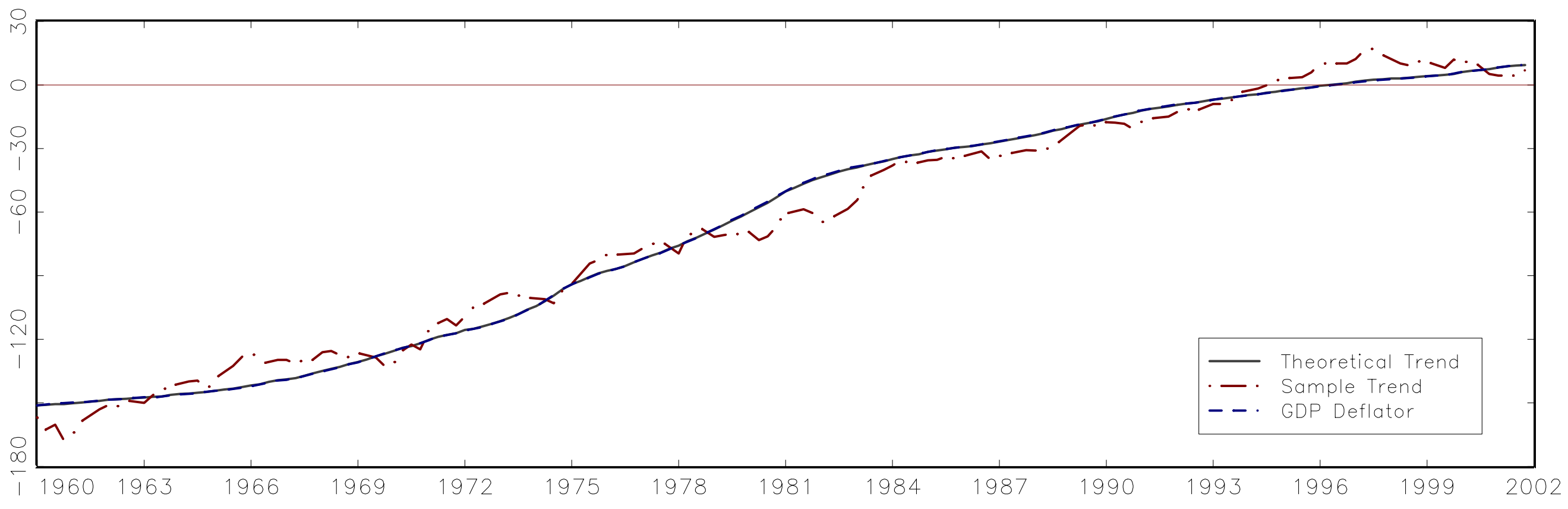

Sample Phillips Curve Cycle and 1-Standard Deviation Band of Yun-Sticky Price Model

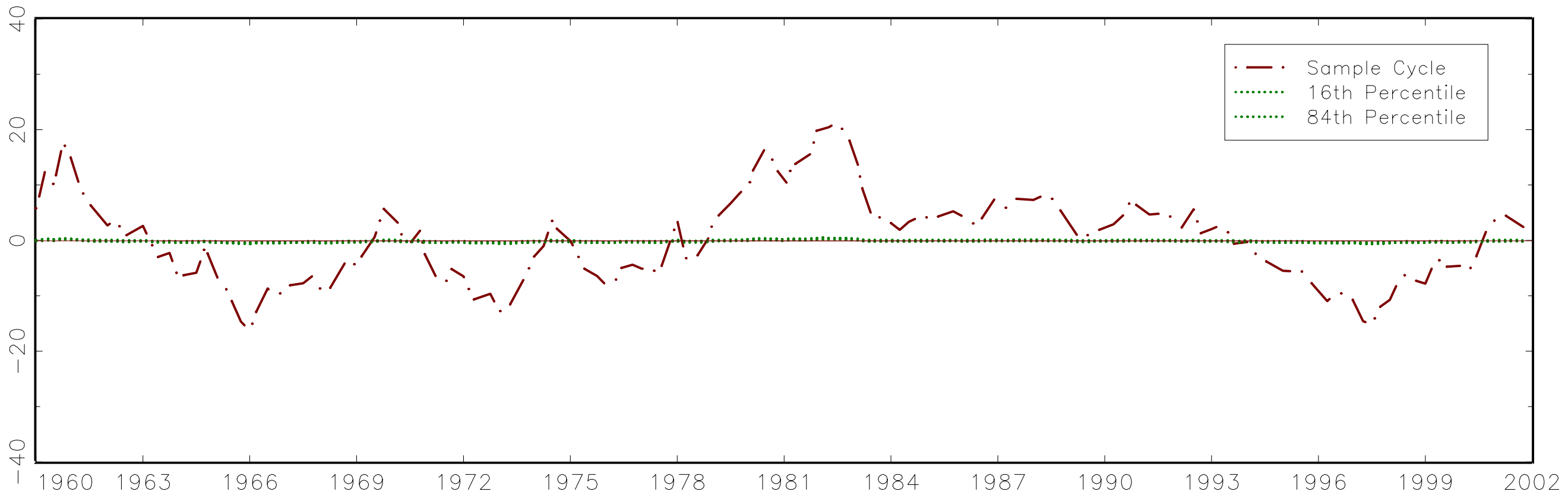


Figure 4: Search-Sticky Price DSGE Model

Search-Sticky Price Phillips Curve Trend, Sample Phillips Curve Trend, and Actual Price Level

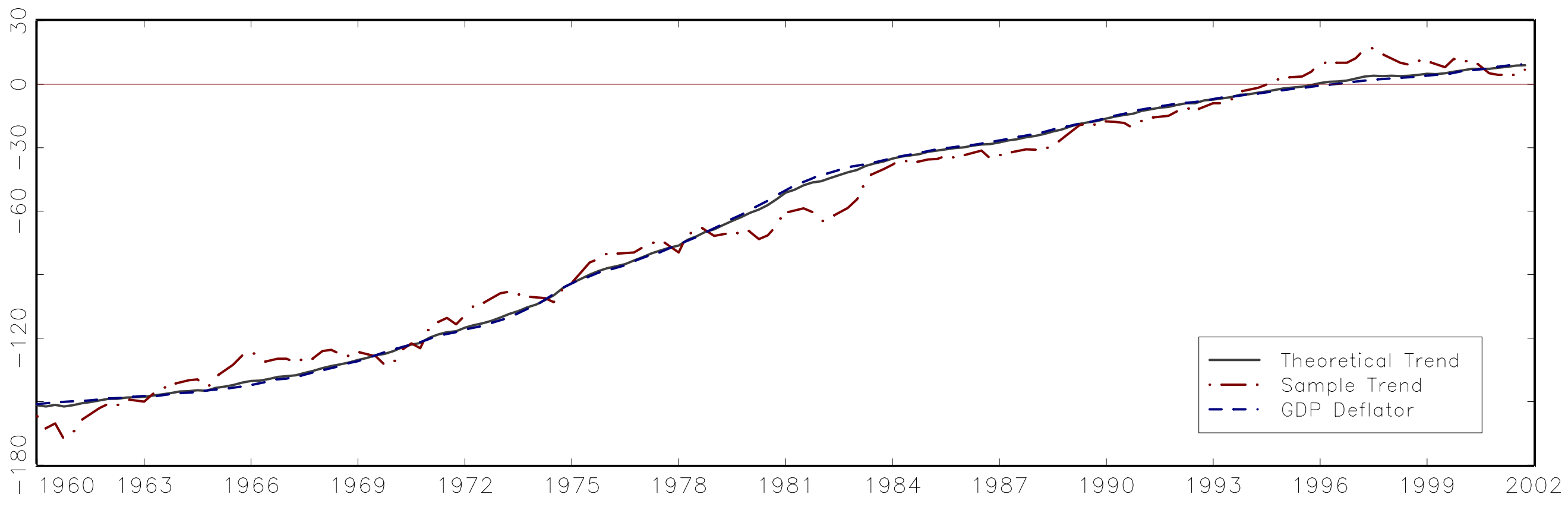

Sample Phillips Curve Cycle and 1-Standard Deviation Band of Search-Sticky Price Model

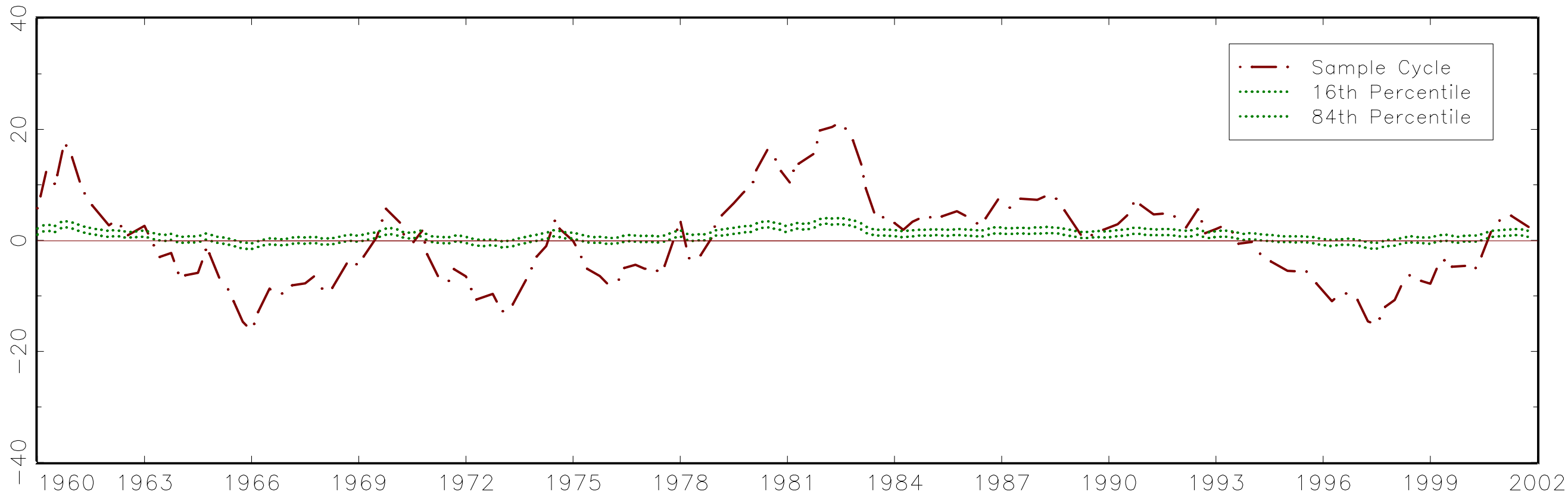


Figure 5: Search-Flexible Price DSGE Model

Search-Flexible Price Phillips Curve Trend, Sample Phillips Curve Trend, and Actual Price Level

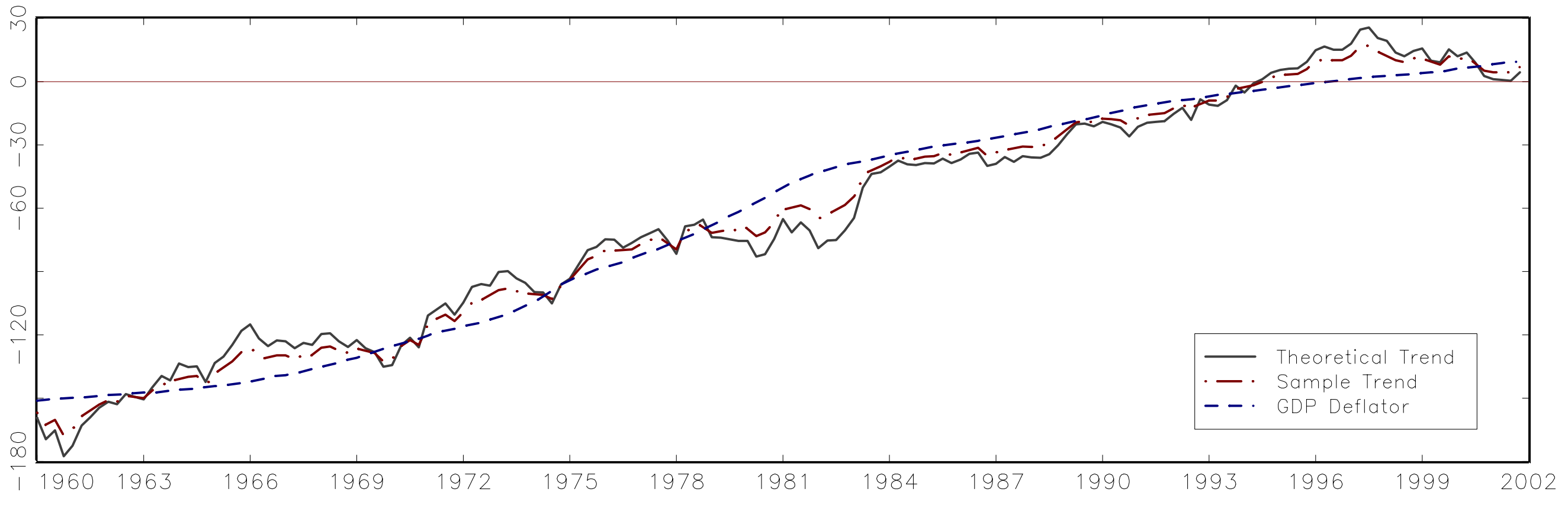

Sample Phillips Curve Cycle and 1-Standard Deviation Band of Search-Flexible Price Model

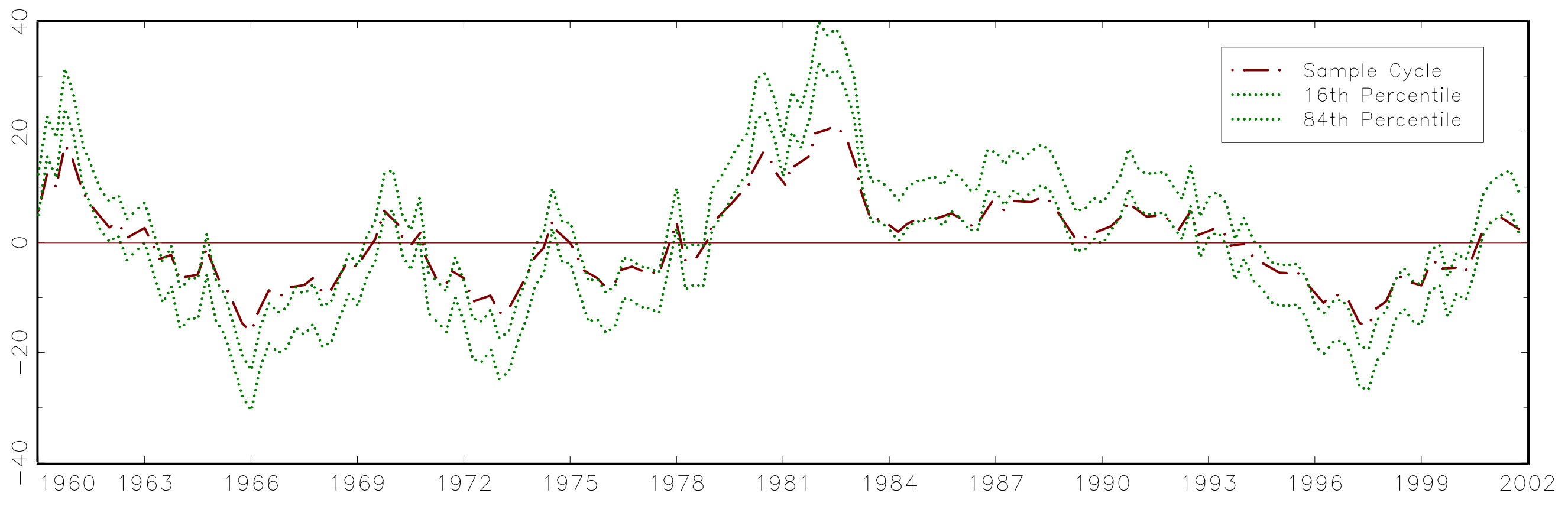

